\title{
توظيف الإعلام الالكتزوني خارطة أكاديمية لتطبيق التعليم الالكتزوني في التعليم
}

م.د. سماد عادل القيسي/ كلية الاعلام/ الجامعة المستنـصرية

م.د. علاء صسين جاسم/ كلية اللغات - جامعة بغداد

\section{مستخلص البحث}

تنافش هذه الدر اسة فكرة اقحام قو الب اعلامية جاهزة جديدة ومبتكرة من خلال تطبيق نظلام مقترح للتعليم الالكتروني على طلبة المرحلتين الثانية و الثالثة في كلية الاعلام بجامعة بغداد بغية قياس آرائهم و اتجاهـاتهم نحو الاسلوب المقترح كونـه يختلف تمامـا عن طريقة التعليم التقليدية المتبعة، اذ اظهرت نتائج التحليل الاحصائي تجاوب وتفاعل الطلبة اسلوب التعليم الحديث وهو مـا يعكس الانسجام النفسي من

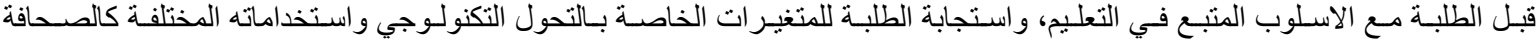
الالكترونية، والاذاعة عبر الانترنيت ، و التلفزيون عبر الانترنيت، والمدونات ، و المواقع التفاعلية مثل المنتديات وسـاحات الحوار المكتوبـة، و المجموعات البريديـة (مثل: الفيس بوك)، و المو اقع الالكترونيـة التي تضم عدد كبيرمن عروض الفيديو صـغيرة المدة (مثل : اليوتيوب) بالاضافة الى الاعلام من خلال الهو اتف المحمولة .

كم كبير من المعلومـات يتدفق كل يوم في ثنايـا الصحف الالكترونيـة وفي الأفلام والمو اقع الالكترونيـة الخاصـة بالمؤسسـات

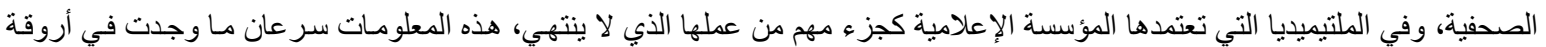
المؤسسات التعليمية، التي كثير ا ما تستخدمها في طر ائق التعليم وفي توضيح المعارف وفي تطبيق الاتجاهات التربوية و الفكريـة، لتؤسس بذللك

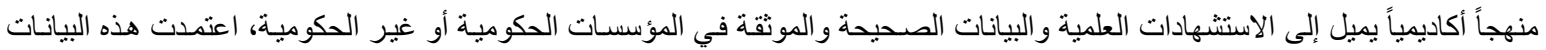

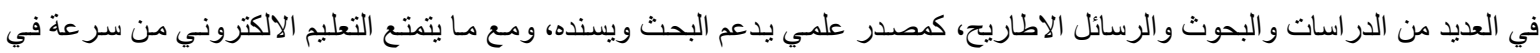
التو اصل أو الاتصـال، كان لابد ان يتبنى جملة من البيانـات السريعة والحديثة أو المتجددة، كي يعتمدها في البحوث العلميـة أو في المنـاهج

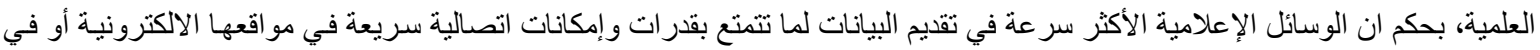

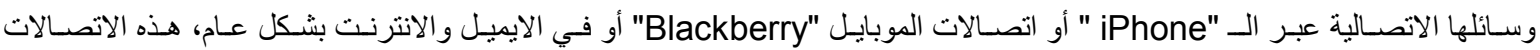
استو عبت كما هائلا من البيانات العلمية و الوثائق والحقائق، لتقدمها على طبق من ذهب إلى الباحث و الدارس من طالب أو أستاذ، ليتمتع بمورد علمي متنوع ومتعدد، أثبه ما يكون موسوعة علمية شاملة لكل العلوم، من هنا وجد الباحثان ان العلوم تتقدم كثير ا مع التكنولوجيا الاتصـالية،

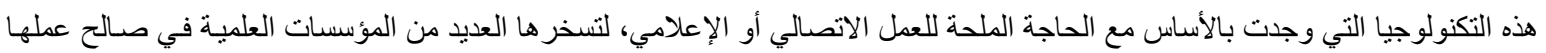
الأكاديمي كي تحقق وثبة في عملها البحثي أو التعليمي بشكل عام، والـ"Electric Learning" التعليم الاككتروني بشكل خاص.

الاقدمهة

ان اسـتخدام التقتيـات و المعدات الاتصـالية، والتقنيـات الاتصـالية كالإنترنـت أو الهـاتف الخلوي منتل "Iphone- blackberry" أو معدات الـ"Data show" و غير هـا من التقتيـات، سـاهمت في تطوير أو تمكين أو تحسين الأداء التربوي والتعليمي في المؤسسات الأكاديمية التربوية والتعليمة، فلهذه التقبـات إمكانية في زج أو ضـخ كم كبير من المعلومـات والبيانـات، التي كثيرا مـا يحتاجها المـتعلم في تعليمسه، أو يحتاجها الباحث في بحوثة العلمية. حيث شكل التعليم الالكتروني ظلهرة جديدة من ظواهر التعليم بحكم انه قد اوجد نوعا جديدا من الاكتساب المعرفي عبر تقنياته، التي تحقق مزيداً-- من المكاسب بالجهذ والوقت و الكلفة، حيث. تلعب وسائط الإعلام المتعددة التي يطلق عليها "Multimedia" دوراً كبيراً في تفسير وتحليـل المعلومـات و البيانات، لتحقيق الفه و الإدر الك للمعلومات، وكما بذكر احد الباحثين في رسـالته توظيف الوسـائط المتعددة في المو اقع الالكترونية الصحفية العر اقية (الوسائط المتعددة كما يثير المختصون تمكن من استخدام مزيج من عنصـرين أو أكثر مـن النص والصـورة والصـوت و الفيديو والرسـوم المتحركة وبرمجيـات الكومبيوتر بمـا يساعد على تقديم الرسائل بشكل جيد ويحسن من شكل المعلومات وطريقة فهمها للمتلقي. 
قد يتبادر إلى الذهن من ان ثمـة تسـاؤلات ستطر ح لو افترضنا الدور والوسيلة الاتصـالية في مجـال التعليم بشكل عام، أهمها ان البحث العلمي يعتمد المصـادر العلميـة الموثقة من قبل المؤسسـات العلميـة، وهنـا تجد الباحثة من ان العمل الاتصالي أو الإعلامي هو الآخر وبحكم مـا يستعرض من بيانات وحقائق لا يمكن

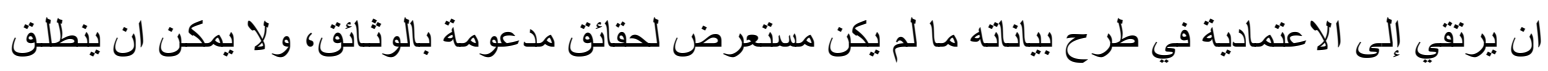
أو يستمر بعمله ما لم تكن هناك جهات رقابية ومؤسسات ونقابات ومنظمات تتابع وتر اقب عملها بشكل دوري و وباشر، كما أنها لا يمكن ان تستمر بعملها كمؤسسة إعلامية، مـا لم تتمتع بالمصداقية، بحكم ان المتصفحين

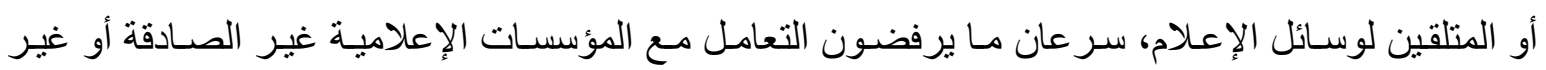

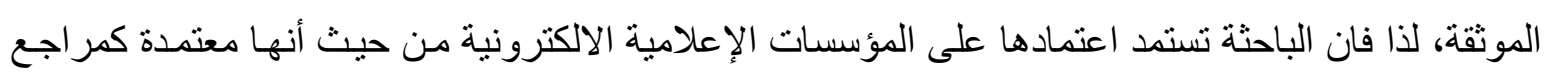
للبحوث العلمية والدراسات الأكاديمية المعتمدة في الكثير من الدر اسات العلمية.

\section{مشكلة البحث وأهميته:}

ربما تختلف المسميات بشأن الموضوع الذي نتناوله في بحثنا، من حيث ان مشكلة البحث قد تشكل

مكسباً هاماً للبحث العلمي، بحكم تسليطها الضوء، على ظاهرة تسللت بشكل انسيابي للمجتمع التعليمي، ولان

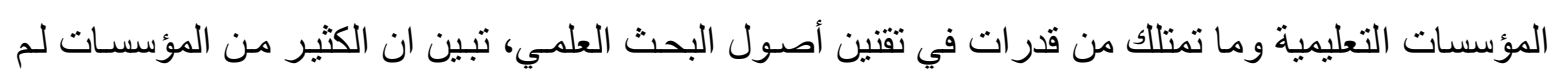
تَبدِ اعتر اضها على اعتماد البيانات الصادرة من المؤسسات الصحفية في البحث العلمي أو في طر ائق التعليم أو الاكتساب المعرفي، حيث يبين الدكتور أبو طالب سعيد في كتابه علم منـاهج البحث ان المصنسادر كثيرة التي تعتمدها البحوث العلمية (مصادر المعلومات باللغة الانكليزية التي تشمل أولا كتب المراجعيد.... الصحف،

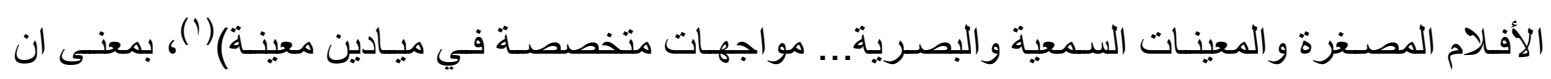

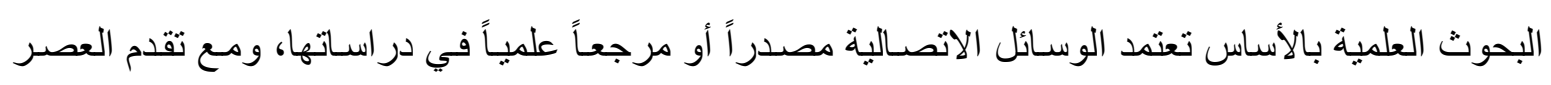
و تقدم الوسائل الاتصالية واعتماد التقنيات الديجيتال و الانترنت، طفت على السطح ظـاهرة الإعلام الالكتروني

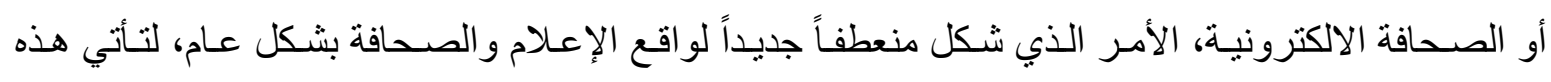

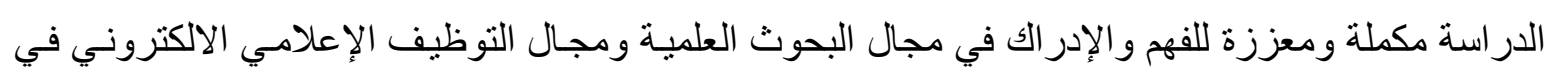

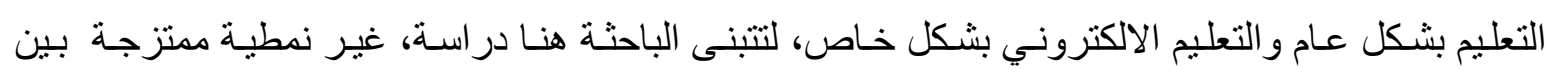

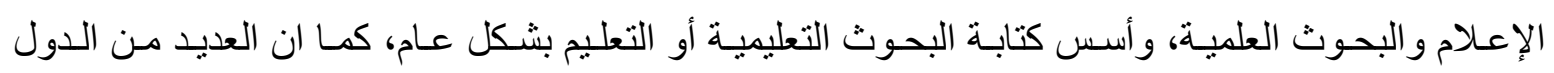
المتقدمة باتت معتمدة على الكثير من وسائل الإعلام في تعليمها، وقد أثـارت الدكتورة فردوس عبدالحميد

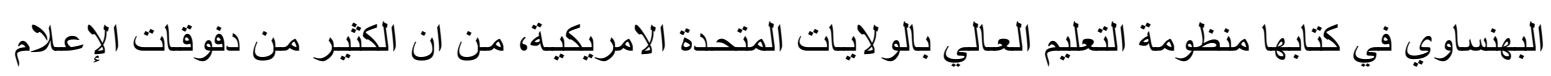
تحقق جملة من المصـادر المعتمدة في تحقيق منظومـة الـ "Distance Learning" التعليم عن بعد في سي أمريكا، حيث تقول (اللجوء إلى شبكة المعلومات "The internet" في موقع معين، يحدد للطالب.... وسـائط أخرى مألوفة للتو اصل، مثل تداول المـادة المسموعة "Audio Conference" في تسجيلات مذاعة يمكن

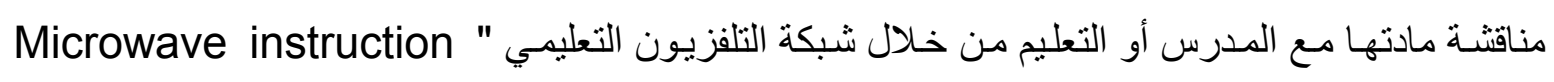
television

وسائل تواصل "Interactive Media"). 
من هنا يجد الباحثين ما تعتمده البحوث العلمية يستند إلى الصحف و الى مـا تستعرضـه بعض وسـائل الإعلام، وبغية اعتماد مشكلة تستحق الدر اسة في بحث علمي، ارتى الباحثان صياغة مشكلة بحثهما على وفق التسـاؤل الآتي: مـا مدى الخدمات التـي يقدمها الإعلام الالكترونسي في التعليم الالكتروني باستخدام تقنيات

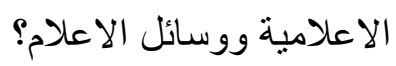

\section{أهد|ف البحث: اف}

يهدف البحـث الـى الكثـف عن مـدى استفادة الـتعلم في التعليم الالكترونـي مـن وسـائل الإعـلام الالكترونيـة في تعليهـه الالكترونسي، و إيضـاح حجـ الاسـتفادة ومعدل التـفق الإعلامسي الذي يرفــ التعليم الالكتروني بالبيانات الهامة و المعارف و الإحصاءات و الوثائق و الصور و الأفلام التي تدعم التعليم الالكتروني.

\section{هدود البمث:}

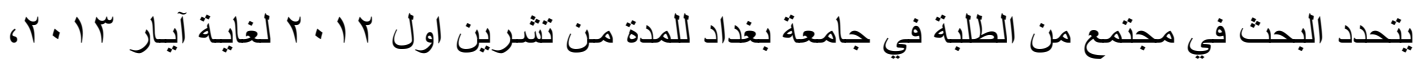

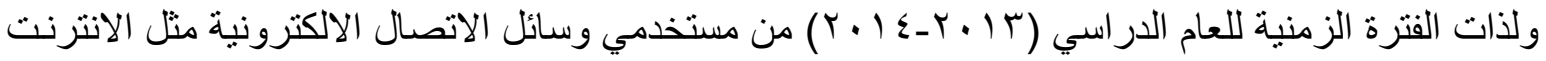
أو الصحف الاكترونية والمواقع الالكترونية، أو المواد الفلمية أو المواد المسموعة المسجلة.

الدراسات السابقة:

قام الباحثنان بالبحث عن المصـادر العلميـة والمر اجع التي تناولت الموضـوعات المقاربـة لدراستهها، إلا أنهما لم يجدا دراسة أو بحثاً متخصصـاً عن الموضوع الذي اختاره الباحثان في بحثها العلمي، إلا أنهـا وجدا بعض الدراسات المقاربة التي يمكن ان تسند أو تدعم البحث، والتي يمكن إيجازها على وفق ما يأتي:

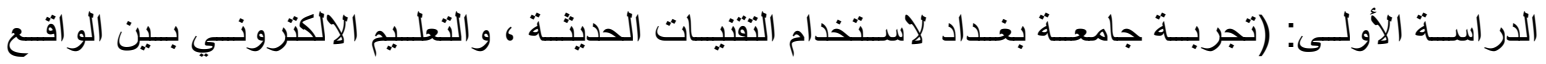

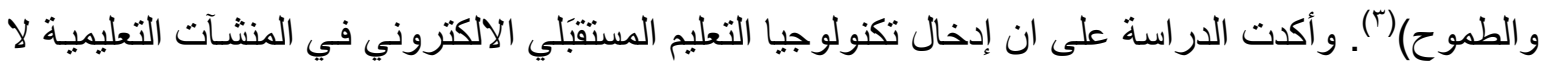
يلغي عناصر وأساسيات وخصوصيات نظم التعليم الحالية، بل يضيف إليها مميزات تسـاعد وتسـهل الاتصـال التعليمي التربوي التفاعلي في داخل وخارج المنشآت التعليمية فضلا عن تطوير المحتوى للمناهج والمقررات الدر اسية لإثر اء العملية التعليمية و التدريبيـة في آنٍ واحد. وقد تطرقت الدراسـة إلى أهم المبادرات التي تم تتفيذها في جامعـة بغداد من أجل الاتصـال بمصسادر الخبرة والتكنولوجيـا، وهي: برنـامج تضيبف الأسـاتذة الزائرين عن طريق استخدام تقنية الصفوف الالكترونية الذكية، عبر الانترنيت بالتعاون مع جامعة تكنولوجيا التعليم الالكترونسي في كندا (IESI)، ونُفذت • V محاضـرةً مباشـرة من مختلف دول العـالم. و الثـر اكة في مبـادرات تطوير التعليم الحديث و المصـادر الالكترونيـة والمختبرات عبر الانترنيت مـع معهد ماسوشتس للتكنولوجيا (MIT) ، مثل: مبادرة التعليم الاكتروني لتطوير البر امج التعليمية لمـادتي :الرياضيات و الفيزيـاء للمدارس الثانويـة على وفق المعـيير العالميـة (LINC-MIT) ، فضـلا عن المشـاركة بـالمو اقع الانعكاسية، المشـاركة بفعاليـة نشـر ثقافـة استخدام تقنيـات التعليم الحديثـة وتكنولوجيـا المعلومـات في التعليم والتـدريب الجامعي عن طريق تنفيذ برنامج تدريبي متخصص ومستمر في هذا المجال، و لأكثر من ( . . آ) عضو من أعضاء الهيأة التعليمية في جامعة بغداد. المشاركة وبفعالية في نشر و استخدام المصادر الالكترونبة والمجلات العلمية المتوفرة على شبكة المعلومات الدولية، وتوسيع قاعدة المستخدمين ضمن مشـروع المكتبـة الافتر اضية 
العلمية العر اقية (أكثر من خمسـة الآلف وخمسمائة مشترك). البدء بأول مشروع تعلم الكتروني مختلط مـع مركز تعليم اللغة الانكليزية في جامعة "اوريكون" في الولايـات المتحدة الأمريكية ، وقد شـارك بـه أكثر من

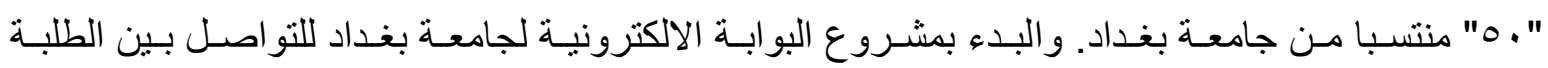
و التعليميين وإدارة الجامعة بصورة مستمرة. و التعاون مع فريق عمل من شركة " مايكروسيستمز" لاستخدام وتطوير بوابـة الكترونيـة للمكتبـة الافتر اضية العر اقيـة باستخدام تقنيـة "CVS" ، ومنصــة التطوير المفتوح .JAVA"

الدر اسة الثانية ()): (البرنامج الريادي للتعليم الالكتروني الموجه بالتعاون بين جامعة بغداد وجامعة اوريكون

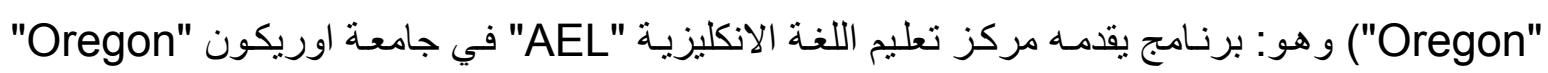

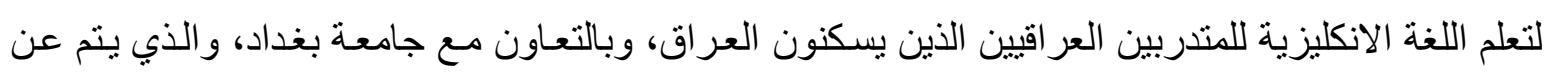

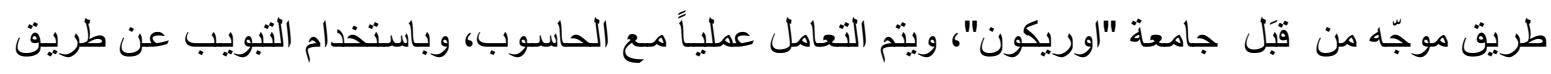

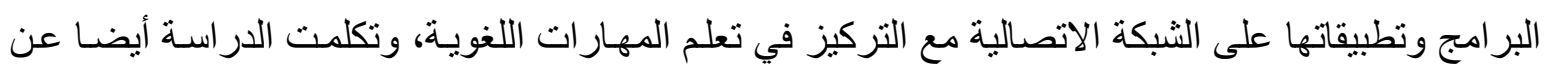
ثلاثنة مصسادر للتعلم يستخدمها المدرب بهذا البرنامج، وهي: المقررات الدراسية، والتعلم الذاتي باستعمال البرامج، و التعلم الذاتي باستعمال مصادر الثبكة.

هن:هج البمث:

اعتمد البحث المنهج المسحي "Survey Method"،و هو المنهج الذي عـادة مـا يسعى فيـه الباحث الى مسح الجمهور المستهدف، لغرض الوصول إلى ارتباطات "Correlations" معينة ، أو البحث عن قيم

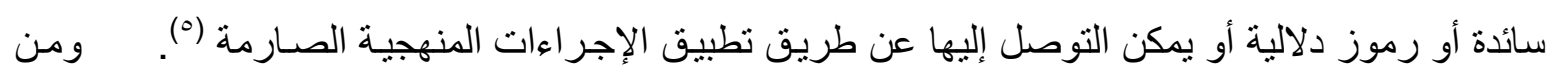
ثم استخدمت الباحثة الاستبانة كأداة لتحقيق أهداف البحث بأخذ عينـة عشو ائية من الطلبة لاستطلاع آرائهم وتصور اتهم حول موضوع الدراسة.

استندت الباحثة في در استها على مجتمع من طلاب المرحلة الثانية والثالثة في قسم العلاقات العامـة

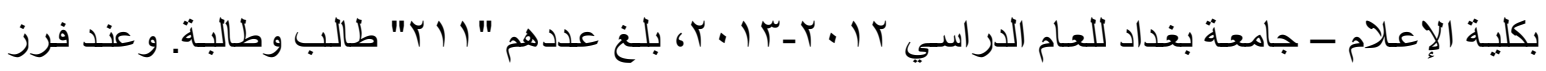
الاستبانات تبين بأن هناك (ץ) استبانات غير صالحة للتحليل إحصائيا فتم استبعادها، وبهذا اصبح حجم.

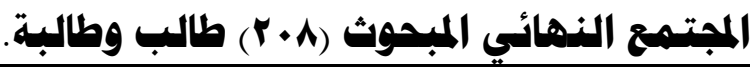

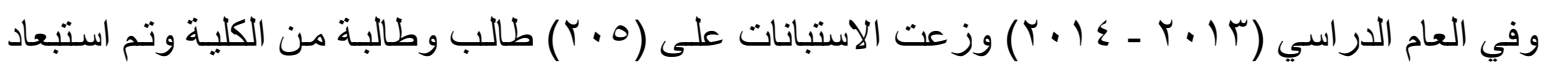
(0) استمار ات لعدم صلاحيتها للار اسة، ليصبح حجم المجتمع النهائي المبحوث ( ( . ب) طالب وطالبة.

بغية التوصل إلى نتائج موضـوعية ذات قيمـة أكاديمية، اعتمدت الباحثة الدر اسـات الاستقصـائية في الحصول على المعلومة من خلال الاستبانة، حيث قام الباحثان بإعداد استبانة بحثية توزع على العينة العمديـة

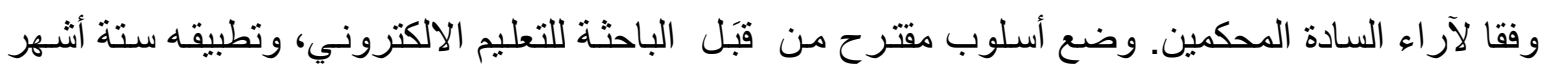

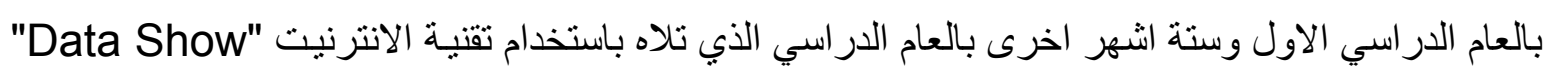




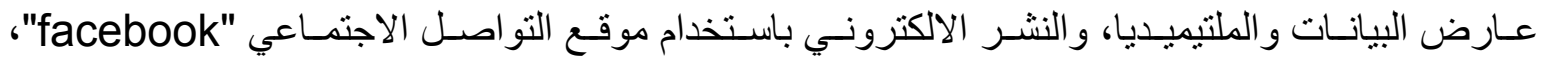
Torch, Firefox, " والاتصـال الالكترونسي عبر البريــ الالكترونسي لكل مـن محركات البحث مثنل Explorer, Google"، وبعد ذلك عمد الباحثنان إلى استخلاص النتائج، بعدها قام الباحثان بصياغة

\section{التوصيات والقدمهات والدراسات المستقبلية.}

1لإطار النـظري:

التوظيف الإعلامسي: التطورات الهائلـة في تكنولوجيا الاتصـال، سـاعدت في إيجاد نوع ووسيلة جديدة في المعرفة والتفكير، بل وأسهمت في تطوير المعرفة عبر آلياتها، التي تمكن الإنسان من استخدام التكنولوجيا للوصول إلى العديد من المعارف والمعلومـات والحقائق والأحداث أو الأخبار ومـا إلى ذلك عبر التكنولوجيا الاتصالية، والتي تتطور يوماً بعد يوم، وتتقدم مع تقدم العصور وتطور ونمو الإنسـان، فعلى سبيل المثنال ظهرت الصـورة الفوتوغر افيـة لأول مرة، في القرن الثامن عشر، وقد اعتمدتها الصحافة منـذ ذلك الحين لتوصيل أفكار ها، بينما اعتمدت الآن الصـورة وتقنياتها وبر امجها الكر افيكية في تحقيق مزيد من المنجزات و المكاسب، لما تحقق من أنواع جديدة غير الأنواع المعتمدة عليها في الصورة قبل قرن مثلا، كذلك هو الحال مع واقع التعليم الذي شـهد هو الآخر تطورا ملموسـا مـع تطورات وتقنيات التعليم و التدريب، حتى توسعت وتحسنت وتطورت عمليات التدريب والتطوير والتعليم بشكل عام، اثر الوسائل المستخدمة في التوصيل والتي اعتمدت بالأسـاس في المؤسسـات الإعلاميـة كمعدات أو وسـائل اتصـال جماهيريـة، من هنـا تجد الباحثنة ان لوسائل الإعلام دوراً مهماً في استخداماتها بالتعليم والمعرفة، ومع تطور هذه الوسـائل تطورت وسـائل التعليم اثر تقدم تكنولوجيا الاتصال، لتعتمد الكثير من المؤسسات التعليمية على وسـائل الاتصـال التي يمكن ان يكون للملتيميديا دور حيوي فيها، وكان للتوظيف الإعلامي أهمية في تيسير وتسهيل التعليم لاسيما التعليم الحديث "التعليم الالكتروني" و الذي يتعدد التقنيات التواصلية الالكترونية، وهنا لابد من توضيح مفهوم التوظيف على أساس أنها مفردة جاءت في اللغـة العربيـة (المؤازرة و الملازمـة ، و استوظف الثـئ استو عبه) (ج)، و الباحثنان هنـا يؤكدان بـان التوظيف الذي يعنياه في بحثهــا، هو الاستخدامات للتقنيات و المعدات الاتصـالية، بمعنى القدرات التي يمكن تحققها المعدات والثقنيات الاتصـالية كالانترنت أو الهاتف الخليوي مثل " lphone"blackberry أو معدات الـ"Data show" و غيرهـا من التقنيات، في تطوير أو تمكين أو تحسين الأداء

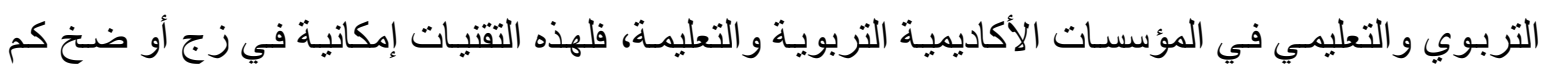
كبير مـن المعلومـات والبيانـات، التي كثير ا مـا يحتاجها المتعلم في تعليمـه، أو يحتاجها الباحث في بحوثـه العلمية، وكانت نوال الصفتي قد بينت في كتابها مفهوم الصحافة الدولية من الإمكانيات التي تقدمها الصحافة عبر تقنياتها المتاح استعمالها أو استخدامها أو تسخير ها للتعليم حيث تقول عن الصحافة وقدر اتها (الحصول

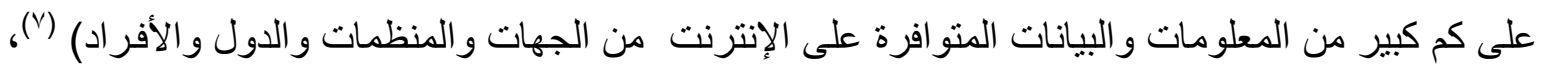
و الإنسان وما يمتلك من فضول في حب التعلم أو الاكتشـاف، يبادر إلى المعرفة عبر كل الإمكانيات المتاحسة

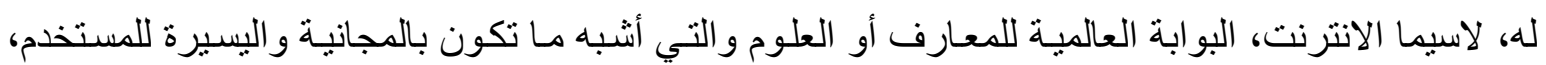
التي يمكن من خلالها تجميع اكبر قدر من البيانات و المعارف و المعلومـات للعديد من الموضو عات و القضـايا 
و الأفكار التي يتعامل بها الناشطون في مجال التعليم أو المشتغلون عليه مـع التعليم عبر مـا يسمى بـالتعليم الالكترونـي، وهنـا يذكر المنظر الأمريكي الفن توفلر في نظريته التـي يطلق عليهـا نظريـة الموجـة الثالثـة

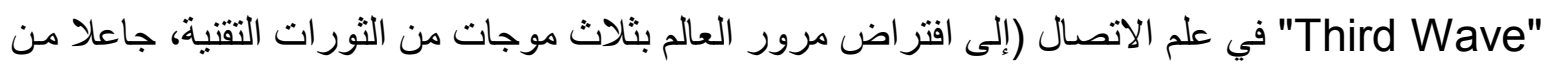
تقنية المعلومات الموجة الثالثة التي تعد البؤرة الحيوية التي تركز عليها جل التغيير ات الحاسمة التي نجح الإنسـان في تحقيقها ضـن سـله العلمي و التقني) (^)، بمعنى ان موجـة جديدة قد حلت في مجـال التعليم

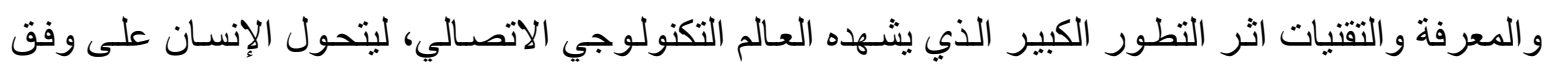
قدر اتـه البسيطة إلى مثقف أو متعلم من خـلال التقنيـات والتكنولوجيـا المتقدمة، التي تستعين كثير ا بقدرات الاتصـال و أدواتـه في نشـر معارفها أو علومها، من خـلال الفكر الإعلامسي أو الاتصـالي الذي يقوم بتبسيط الأشياء وإعادة طرحها على وفق شكل جديد يسهل في فهم المضمون، وهذه العمليات التي نتحدث عنها إنما تتحقق مع مـا تمتلكه قدر ات الملتيميديا في العرض أو الطرح للمعروضـات، من خلال القدرات في التحكم بالصوت والصورة التي تجمع الثكل و عناصره من خط ولون وحركة وكتلة وسطح وظل وضـوء التخ، حيث لا يمكن للمضـامين ان تكون يسيرة الفهم للشخص غير المتعلم مـا لم يتم تبسيطها، فتأتي الملتيميديا كعامل

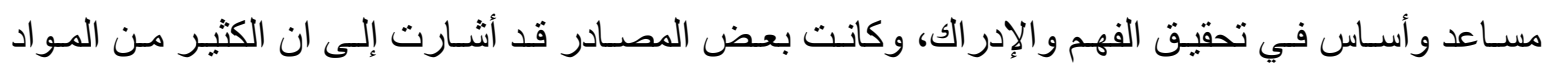

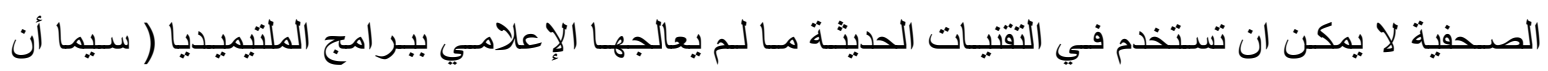
المضـامين و المـواد المنشـورة في المواقع الالكترونيـة الصحفية تبقى أسبرة الجمود و الرتابـة مـا لم تستعن بعناصر الوسائط المتعددة في دعمها وتعزيز هـا وخير مثنال على ذللك المواقع الالكترونيـة الثـهيرة مثل الـ CNN و BBC و MSA Today الجمهور، ولعل هذا ما شجع الباحثة على رصد المو اقع الالكثرونية الصحفية العر اقية ومر اقبتها على وفق مـا

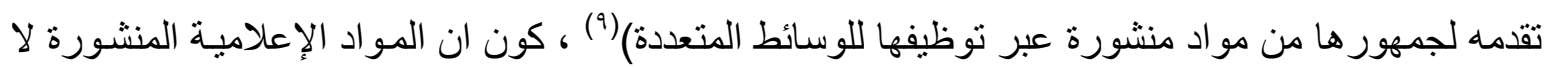
يمكن ان تكون مؤثرة ما لم تجلب المتلقين لها، بمعنى ان المواد الصحفية أو الإعلامية بشكل عام، تبقى راكدة و غير مؤثرة، ما لم تجد لها طريقاً يحقق الانتشار و المتابعة أو التلقي.

قدرات الإعلام لم تكن قاصرة على التعليم أو المعارف فحسب ، بل كانت وماز الت في كل الميادين و الأصعدة، وهو مـا يجعلها تستأسد أو تحقق لها سلطة، بحكم نأثير اتها وقدر اتها على التغيير، ولمـا كانت التقنيات الاتصـالية قد تطورت وارداتهـا بحجم كبير مـع تطور وسـائل الاتصـال، تطورت عمليـات التلقي

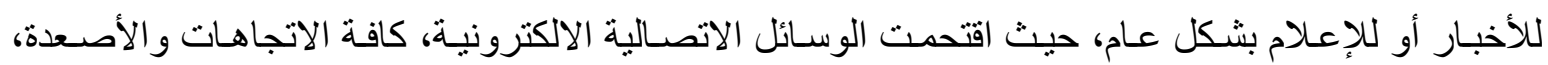

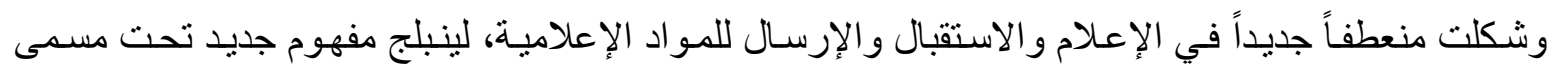
الإعلام الالكتروني، هذا الإعلام الذي تمكن من ان يحقق ثورات هائلة ومنها ثور ات الربيع العربي التي أطاحت بالعديد من الزعماء والقادة السياسيين، (ما قامت به وسائل الإعلام، من تأثير ات هائلة لإسقاط الحكم

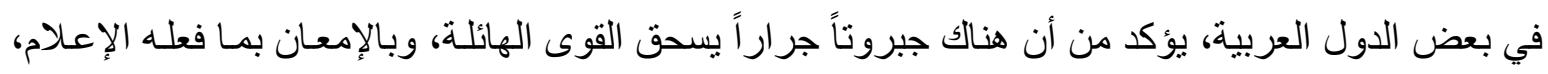
وما رافقه من جهد غير مسبوق في تأجيج المواقف الجماهيريـة، لتغيير واقع الحكم في ليبيا أو في مصر أو تونس و اليمن، و الو اقع أن العديد من المنظرين والسياسيين، يرون انه ربيع عربي، بالوقت انه لـ يكن كذلك

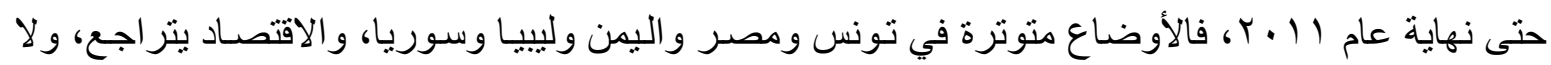


يوجد أي استقرار في هذه المناطق، بـل أن الكثير يرون أن الأزمات مستمرة في هذه البلدان، وحتى هذه

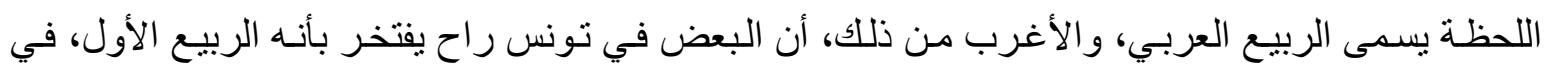

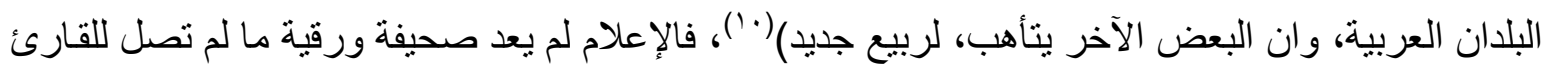

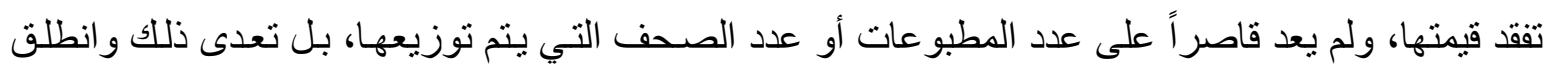
إلى حدود لا يمكن التكهن بها، وباتت تأثير اتـه غير متوقعة وغير معدودة، بحكم ان الاتصـال الالكتروني قد تفوقت أعداده ملايين المرات على الاتصـال التقليدي بالصحيفة الورقية، فالاتصـال الالكتروني عبر الويب سايت على سبيل المثال يصل إلى مليار ات من المتلقين، ويمكن ترجمته بسـهوله عبر المواقع المنتشرة في الانترنت، ليكون الإعلام بكافة لغات العالم بعد ان كان قاصر اً على لغة واحدة فقط أو لغتين لصاحب المؤسسة الصحفية، من هنا جاءت الكثير من النظريات التي تحذر وتنوه من المخـاطر التي يمكن ان يلحق بها الإعلام الالكترونسي مـا لم يكون متقناً ومدروساً، وذلك لأنه يحمل أبعاداً كثيرة جدا، منها الاقتصـادية والاجتماعيـة و السياسية أو الدينية و هكذا، و هنـا تأكيد على ذلك من بعض المصـادر العلميـة حول هذه الأبعاد والتي تفيد

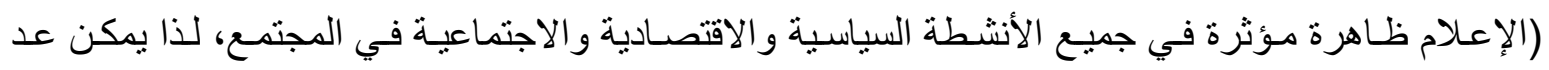
الإعلام الالكتروني و الصحافة الالكترونية تحديدا احد البدائل الاتصالية التي أتاحتها الانترنت، إذ أنها أسهمت في تعظيم الأثر الاتصالي للعملية الإعلامية عن طريق ما تتو افر عليه من عناصر مقروءة ومسموعة ومرئيسة

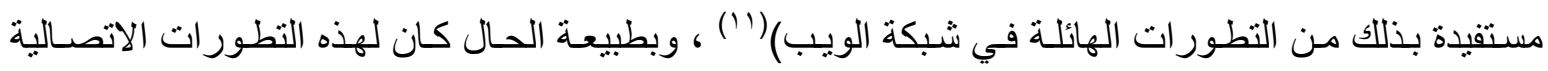
الالكترونية مزيد من الإفرازات و النتائج التي لم يكن منها منوقعا، كأن يزداد عدد الصحفيين بعدد المهتمين

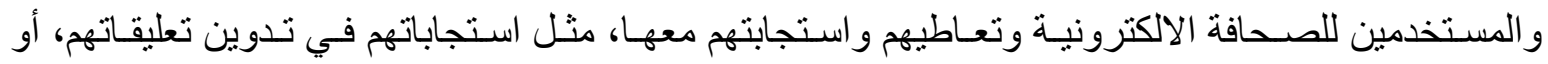
مشـاركاتهم بالمشـاهد الفيديويـة ونشـرها على المو اقع الالكترونيـة أو نشـر البيانـات والصـور و غيرهـا مـن معلومات، وقد عبر عن ذلك غيرت لينباك رئيس تحرير روينرز السـابق في مؤتنمر أقيم في شـهر آذار من

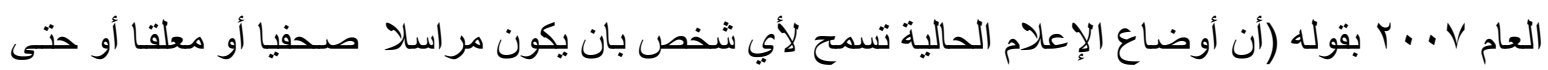
مخرجا سينمائيا وان زمن احتكار الممارسات الإعلامية و السيطرة عليها قد انتهى)('أل. الإعـلام العلمي لا يخفى على الكثير مـن الصـحفيين الأكساديميين أو المهنيين، بـان للإعـلام أنواعـاً

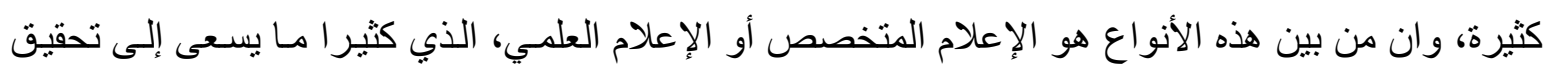
فهم المعلومات و ادر اكها وتسهيلها وتيسير ها عن طريق تبسيط الإعلام الموضو عات العلميـة المعقدة وطرحها للمتلقي في صورة يسيرة غير معقدة كي يستقيد منها بعد ان يتمكن من التعامل معها أو الاستجابة لها، وهو مـا اعتمدته الكثير من وسائل الإعلام في عمها الصحفي أو الإعلامسي لتحقيق الاستقطاب الذي تتشده في عملها الإعلامي، حيث تسعى الكثير من المجلات أو الصحف أو المواقع الالكترونية، الى طرح مزيد من المعلومـات أو الموضوعات العلمية بوسائلها الاتصالية، بغية التأثثر في المتلقي وتتشيعه على متابعة المجلة أو الوسيلة

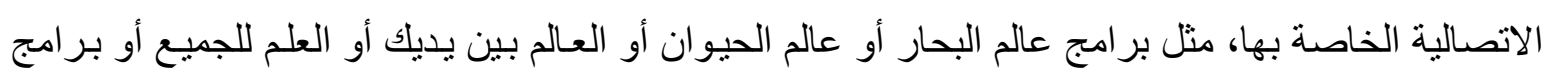

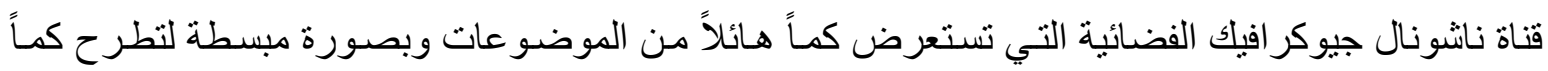
هائلاً من البيانـات و الحقائق العلمية بصورة مبسطة وميسورة الفهم، ليكون الإعلام العلمي رائجـاً ومنتشـراً

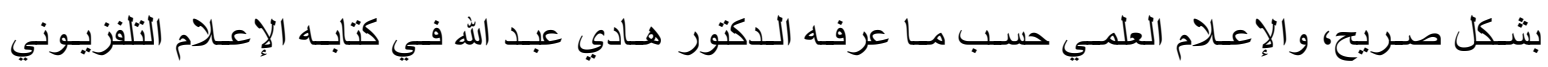


المتخصص، هـو ( نقل المعرفـة إلى الجمـاهير عـن طريـق العـل الاتصـالي، عن طريـق وسـائل الإعـلام

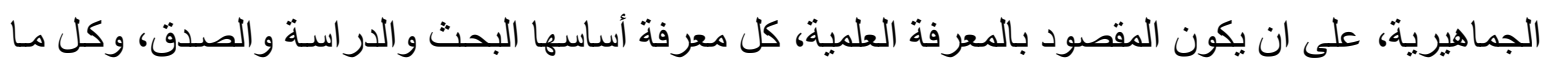
يرتبط أو يتعلق بالمجتمع العلمي الإنساني في ماضيه وحاضره ومستقبله، حيث تندمج في تلك المعرفة العلوم

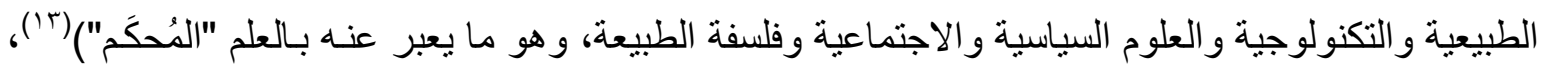
ومع هذه الرغبة أو الميول لدي المتلقين، ازدادت المواقع الالكترونية الإعلامية وغير الإعلامية، لتنشر سيلاً

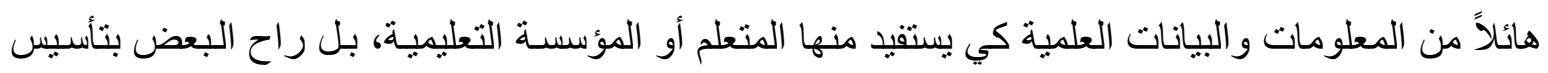
مو اقع متخصصة في بث البيانـات الوثائق مثنل موقع ويكيليكس الذي تخصص بنسريب الوثنائق السرية، أو موقع الوكيبيديا الذي اهتم بنشر المعلومات الموسوعية دون حدود، أو مواقع أخرى كبيرة اختصت بنشر نوع

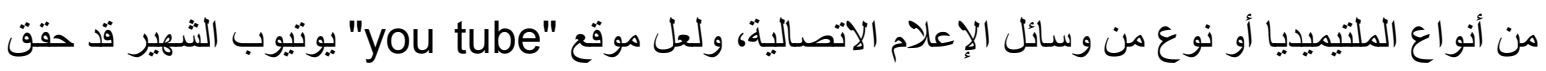

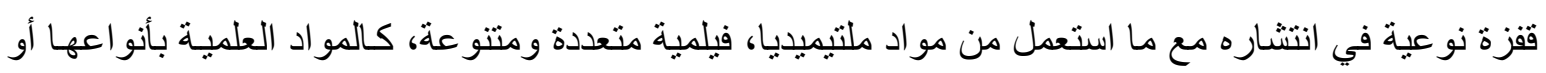
التاريخية أو المنوعات أو الأفلام الروائية أو التسجيلية أو حتى الوثنائق ومـا إلى ذلك من من مواد فئن فيلميـة نـادرة،

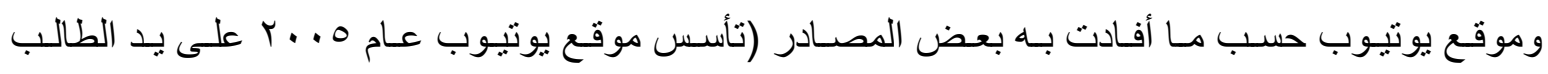

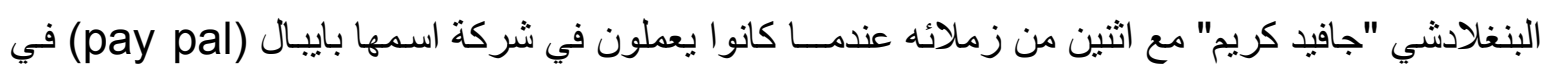

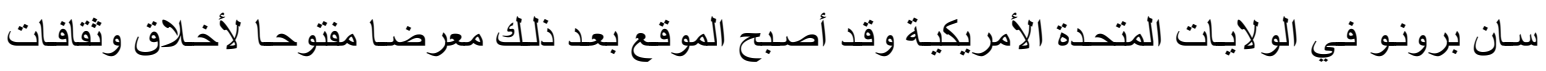

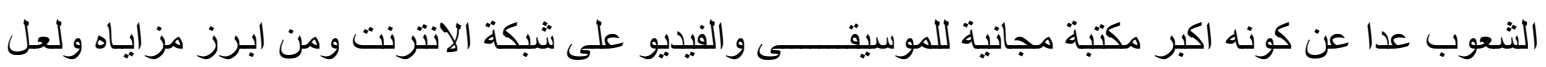

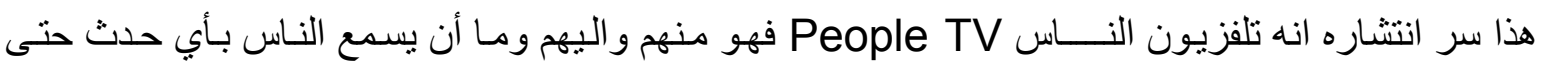

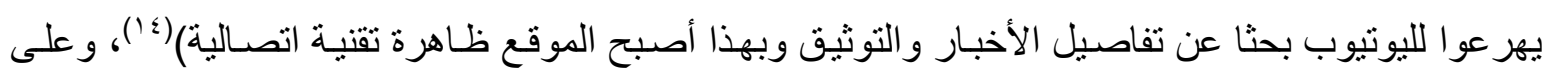

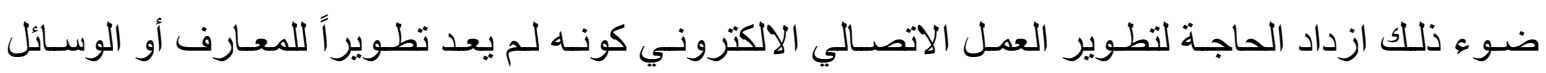

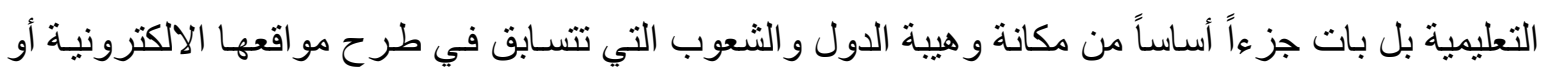
وسائلها الاتصالية الديجيتال، ليؤكد لنا الدكتور محمد فلحي ذلك في كتابه الاتصـال الرقمي و الوسـائط المتعددة (أصبحنا نعيش عصر المعلومـات الذي تقاس فيه مكانـة الأمم والثـعوب عن طريق مقدار مـا تنتجهـ وتبثنه وتنتهلكه من معلومات وما تمتلكه من مؤسسـات وأدوات لاستخدام المعلومات التي تعد المورد الوحيد غير

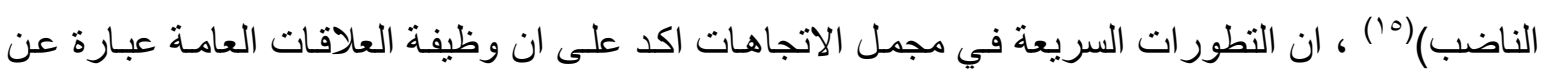
وسيلة للاتصـال في المنظمـات(T')، إذن العـالم يتقدم نحو التطورات الاتصـالية التي تقوم بالعديد من المهام

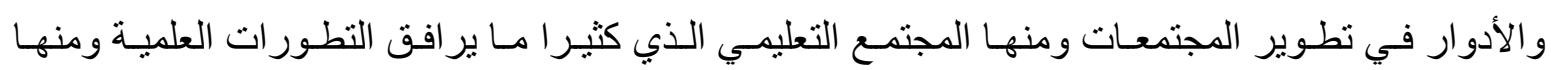
الاتصالية، و لاسيما التعليم الالكتروني الذي أصبح حقيقة ملموسة في العديد من دول العالم.

\section{مفهوم (الوسيلة التعليمبة):}

خطى العالم خطوات كبيرة في مجال الثقافة الالكترونية لمّا وصلت إليه من منجزات التطور العلمي و التكنولـوجي، و التـي بلغت ذروتهـا فيمـا يتحقق مـن تقدم في مجـال التقنيـات المدمجـة للاتصـالات و المعلومات، فقد تعددت الوسائل التعليمية التي وفرتها الثقافة الالكترونية، مثل: الاتصـال التفاعلي وشبكات الانترنيت و المعدات المساعدة في العملية التعليمية ، فاستخدام هذه التكنولوجيا يزيد من فرص التعليم، وتمتـ

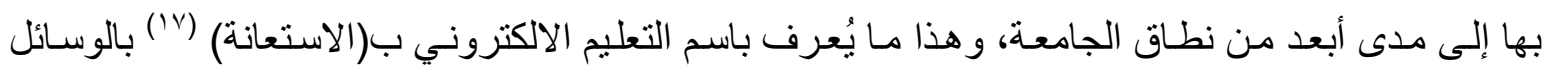


التعليمية التي تُعّد من مكونات العملية التعليمية وضرورية لحدوثها، فأهمية الوسيلة التعليمية من أهمية العملية التعليمية نفسها في أي مجتمع، فهي أي وسيلة بشرية كانت أو غير بشرية، تعمل على نقل رسـالة مـا من

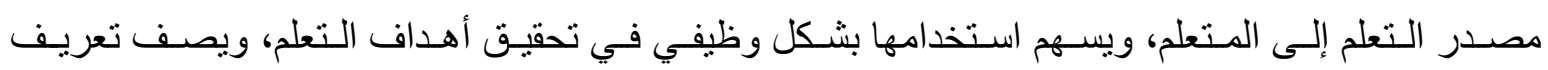
آخر "الوسيلة التعليمية" بأنّها "مجموعة أجهزة وأدوات يستخدمها المعلم لتحسين عملية التعليم و التعلم بهدف توضيح المعاني، وشرح الأفكار في نفوس التلاميذ أما تكنولوجيا التعليم، فتوصف بأنها: استخدام المعلم كل مـا

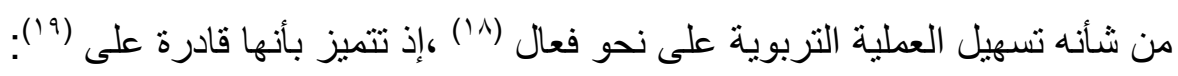
تحسين نوعية التعلم، وزيادة فعاليته عن طريق التماثي مع النظرة التربوية الحديثة التي تُعْد المتعلم محور العملية التعليميـة، تستطيع استثارة إهتمـام الطلبـة، وإثباع حاجـاتهم للتعلم، فلا شـك في ان الوسيائل

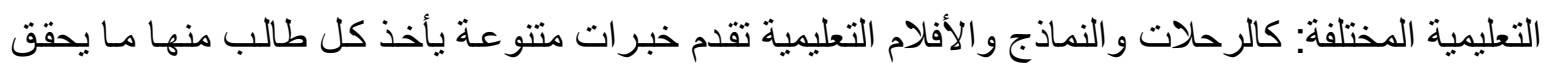
أهدافه، ويُنير اهتمامـه، تؤدي إلى تنميـة القدرة على التأمل والتفكير العلمي الخـلاق في الوصسول إلى حل ونل المشكلات، وترتيب الأفكار وتتظيمها على وفق نسـق مقبول، تحقق تكنولوجيـا التعليم، وزيـادة المشـاركة

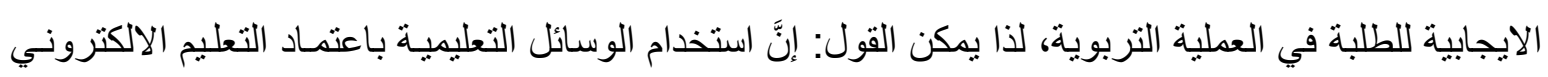

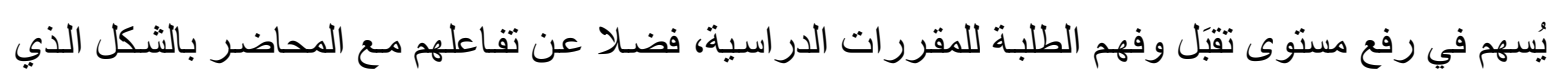
ينعكس على مستوى العلامات المحصلة في الامتحانات النهائية.

مفهموم (التنعليم الالكترونـي)

شكل التعليم الالكتروني وسيلة فاعلة حديثة بامكانها ان تعمل على تطوير التعليم العالي، ممـا يهيئه

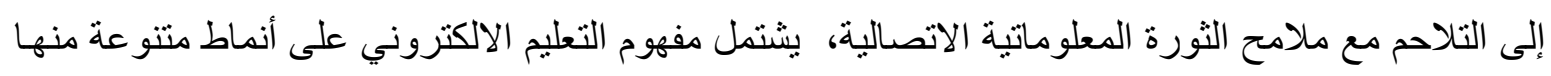
التعلم بالحاسوب ووسائل العرض الاكتروني والتعلم عن طريق شبكة الانترنيت ، و التعلم عن طريق شبكة قو اعد البيانات ، و التعلم في بيئة افتر اضية، وتوظيف تقنية التعلم عن بعد (r.).

وتتقسم مخرجـات مصطلح (التعليم) إلى شقين: يتخذ أولها /الاستفادة مـن قدرة استخدام الأجهزة الالكترونية الحديثة على تسلم وبث مضمون المعلومات أو الإضافة إليها واستبدالها ، في حين يقتصر المخرج الآخر / باستقبال دروس منهجية من مؤسسة تعليمية بشكل مستمر في مو اعيد محددة بعد إجر اء بعد التعديلات

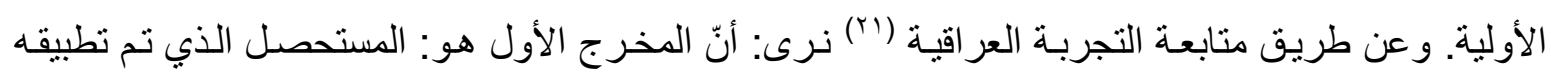

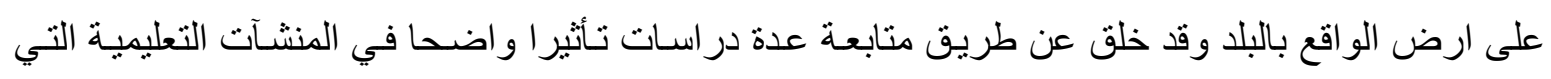

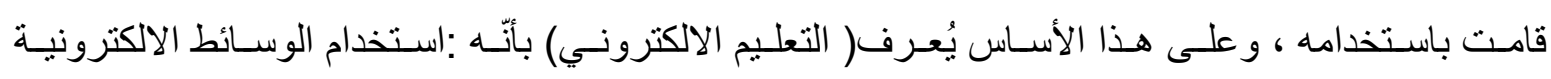

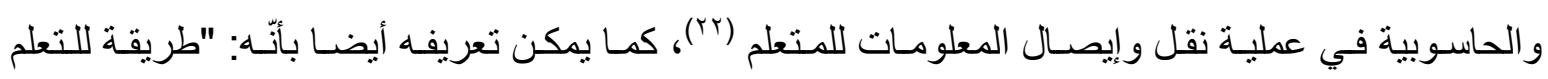

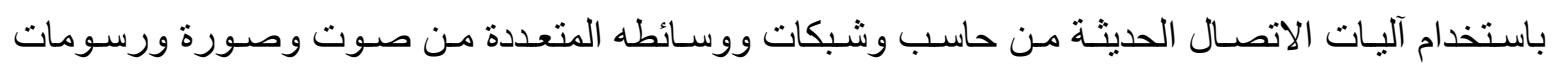
و آليات بحث ومكتبات الكترونية وبو ابات الانترنيت" (rrr)، أو يُعرف بأنّه :نوع من أنواع التعلم عن بُعد يتم

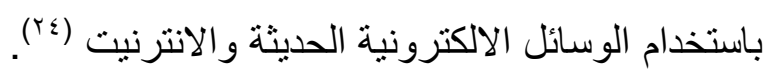




\section{فا علية التعليم 1لالكترونسي}

تتوقف مدى فاعلية التعليم الالكتروني على عدة عو امل أهمها (ror): التكنولوجيا، الأستاذ، الطالب. ويعتمد التعليم الالكتروني اعتمادا كبيراً على التكنولوجيا الحديثة، وخاصـة تكنولوجيا الكومبيوتر وتكنولوجيا

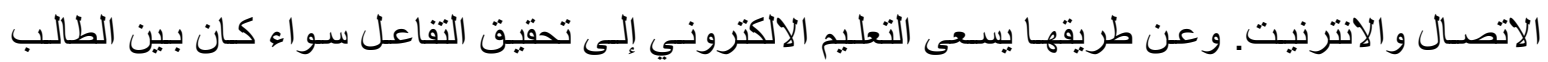
والأستاذ أم بين الطالب و الطلبة الآخرين.

مز ايـا التعليم الالكتروني (بr): للتعليم الالكتروني مزايـا عدة، وهي: التعليم المرن: ويقصد بـه تحقيق مرونـة الحصول على المعلومة واختيار الوقت الملائم للوصول إليها. حرق الزمن: ويقصد به توفير وتنظيم وفت المتعلم والمعلم في التعامل مع البيئة الافتر اضية. الاتصال و التفاعل: ويتم ذلك عن طريق البيئة الافتر اضية. ادخار المال: حيث يوفر التعامل مـع الثبكة بعض المـال المصروف على التقلل والسفر، ويقلل من ازدحام

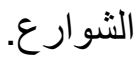

\section{التعليم الافتتراضي:}

هو: ان نتعلم المفيد من مواقع بعيدة، لا يحدها مكان و لا زمـان بواسطة الإنترنت و التقنيات ـ فقد

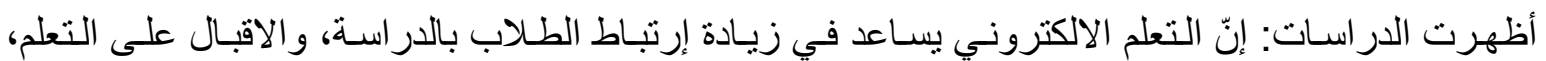
وزيـادة نسبة حضور الطلاب، وهي المتطلبـات الاساسية للتعلم، والتعلم الالكترونسي يمكنه ان يحسن الأداء للمقررات الأساسية، كما ينمي مهارات القرن الواحد والعشرين سواء كان في الدول المتقدمـة أم النامية، ففي وهي در اسة طبقت في و لاية "ماين" الأمريكية برنامج للتعلم الاكتروني في المدارس وشملت أكثر من " . . . ؟ ع " طالب، وأكثر من" . . .0" مدرسـة أوضـحت: إنّ أكثر مـن" . ر\% " مـن القائمين على التعليم أقروا بـأن الطلاب أصبحوا أكثر إلتصاقاً، وأكثر تفاعلا مع العلية التعليمية، وإنّهم أصبحوا ينتجون اعمالا أكثر جودة مئم وقد سجل مديرو المدارس والقائمون على التعليم رأيهم بان التعليم الالكتروني قد زاد من إقبال الطلاب على ولى

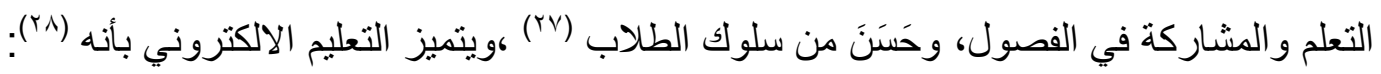
ـ أداة فعالة لنقل المعلومات و المعرفة الصريحة للحصول عليها، وركيزة ثالثة من العملية التعليمية. ـ أداة للتخاطب بين المتعلمين و المعلمين، وللتواصل بين المؤسسات التعليمية ومؤسسات المجتمع الأخرى. ـ أداة للتعلم تخرج عن النطاق الجغر افي للمؤسسة التعليمية، وكذللك نطاق الوقت و أداة تعلم مستمر. تتمثل دو افع اختباره بملائمته ومرونة جدولة أوقات الدر اسة، مما يمنع الغياب عن العمل، ويمثل حلا لتعليم الأفر اد المتباعدين جغر افيا، ويتميز بتتوع المواد التعليميـة، وإمكانيـة التواصل المباثـر وغير المباشـر

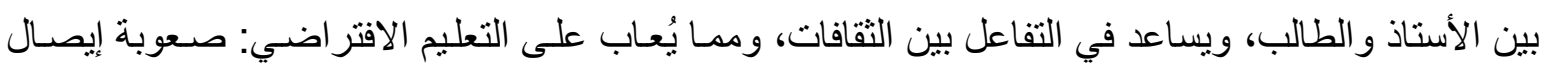

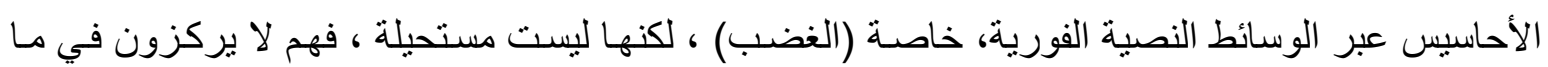


يكتبون على اعتبـار إنّ مكانتهم معروفة لدى الجميـع، وهو مـا يؤدي إلى سوء العلاقة بين الطرفين لكون المعرفة ليست حقيقية او عميقة ، فنر اها تقوم على أسس ثنائية زائفة (r9).

أسلوب التعلبم 1الكترونـي المقترحم :

يقوم الأسلوب المقترح على وضع ستر اتيجيات اتصالية الكترونية فعالة للتو اصل الدوؤب بشـأن مـادة الدر اسة لمرحلتين وتجسيد التعلم الذاتي من خلال طرح مفردات تنمية ذاتية على الموقع الدر اسي الالكتروني الذي انشأ على الفيس بوك لغرض الانتقال من التواصل و التعلم الالكتروني الى التو اصل و التعلم الذكي اي سهولة فتح هذا الموقع على اجهزة هو اتفهم الذكيـة او على اجهزة الايبـاد وغير هـا وذلك في قسم العلاقـات

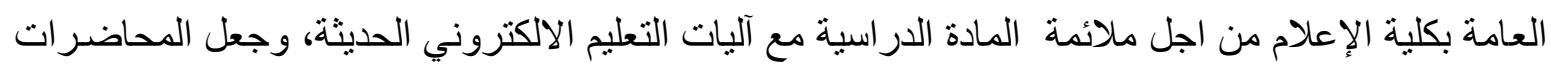

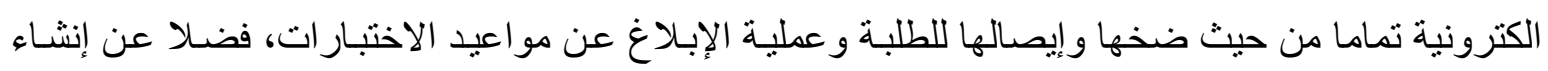
موقع خاص بالمادة العلمية على شبكة الفيسبوك من أجل تثقيف الطلبة أكثر بشأن التواصل الاجتمـاعي بينهم وبين أستاذة المادة بشكل مستمر، بالاعتماد على الوسائل الاتصالية الالكترونية والاجهزة الذكية.

\section{البانب التطبيقي : مجتمهـر البهث}

استخدمت الاستبيان كأداة للبحث للتعرف على ابرز الامور المتعلقة بموضوعة البحث.

استخدمت المنهج العلمي الوصفي في الاستقصـاء حول كل فقرة معينـة عبر مقارنـة اسلوب التعليم لدفعتين در اسيتين من طلبة كلية الاعلام.

\section{الاساليب الاهصائية:}

اسـتخدام اسـلوب النسـب و التكـرار ات في بيـان المتغيـرات الديمو غر افيـة للبحث و اسـتخدام اسـلوب تحليـل المتوسطات في دراسة مدى ادر الك واستجابة الطلبة حول كل محور من محاور البحث. استخدام اختبار مربع كاي لبيان مدى وجود فروقات ذات دلالة احصائية بين اسلوب التدريس لعام r ا ـ r-

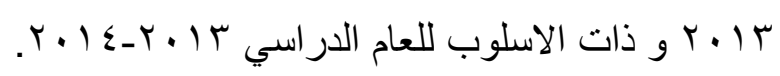
الفرضية الرئيسية: توجد فروق ذات دلالـة احصـائية بـين ادر اك وتفاعل طلبـة كليـة الاعـلام حـول اسلوب ومضمون واليات التعليم الدراسية.

الفرضيات الفر عبة هي: ـ توجد فروق ذات دلالة احصائية بين ادر اك وتفاعل طلبة كلية الاعلام حول طبيعة اسلوب التدريس الحديث. ـ توجد فـروق ذات دلالـة احصـائية بـين ادر الك وتفاعل طلبـة كليـة الاعـلام حـول مضـمون التـدريس لمـادة العلاقات العامة.

* توجد فروق ذات دلالة احصائية بين ادر الك وتفاعل طلبة كلية الاعلام حول آليات التعليم الالكتروني الحديثة في التدريس. 


\section{الجانب التطبيقبي : مجتهـــر الدراســـة}

لاجل التحقق مـن فرضية البحث وتحقيق اهدافه تم اعداد استمارة استبيان شـلت معظم الاسئلة و المتغيرات التي ترى الباحثة أهميتها وخدمتها لاهداف البحث، وقد أخضعت هذه الاستبانة الى التقييم من قبل

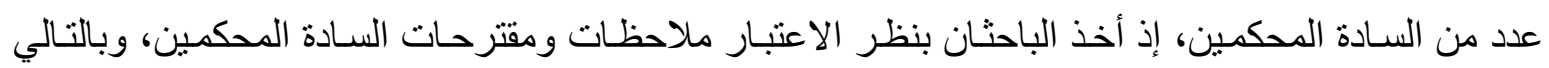

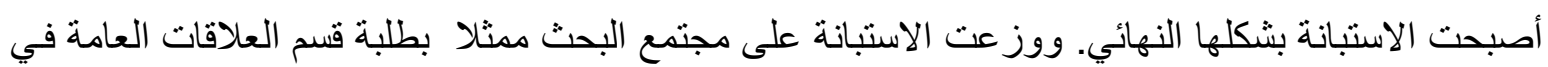
كلية الاعلام جامعة بغداد للمرحلتين الدر اسيتين الثانية والثالثة بغية استطلاع أر ائهم وأجاباتهم حول موضوع

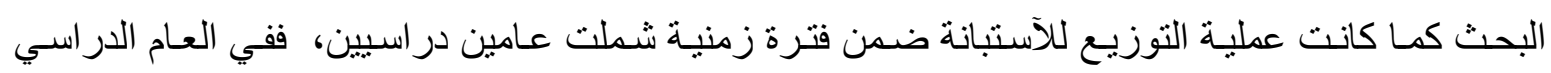

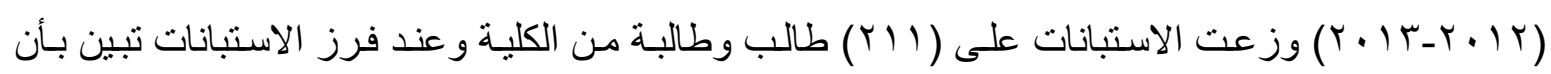
هناك (r) استبانات غير صالحة للتحليل أحصائيا فتم أستبعادها، وبهذا اصبح حجم المجتمع النهائي المبحوث

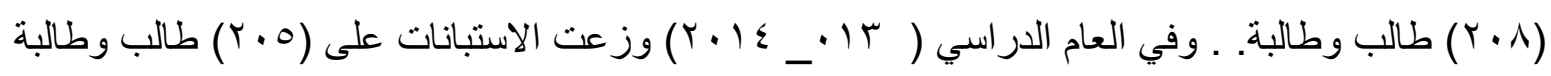
ولدى فرز الاستبانات تبين بأن هناك (0) استبانات غير صالحة للاخول الى مرحلة التحليل الاحصـائي لذات تم

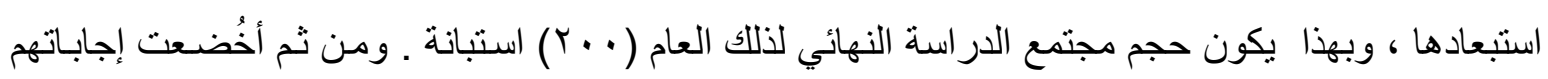

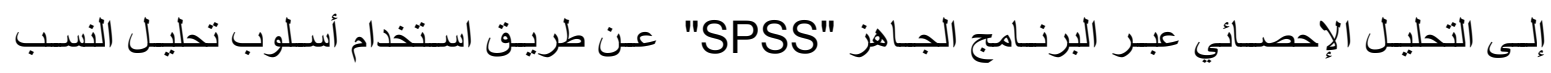
و التكر ارات و التحليل الإحصائي باستخدام أسلوب المتوسطات من أجل اتخاذ قرار بشأن فرضية البحث. وبعد أن نم فرز استبانات العامين الدراسيين، أخضعت اجابات الطلبة في كلا العامين الى التحليل الاحصـائي لبيان ابرز العوامل المؤئرة من وجهة نظر اولئك الطلبة لكل عام در اسي على حدة ومن ثم المقارنـة بين العـامين

الدر اسيين سوية.

\section{1فتبار الثبات للاستبانة:}

وبعد إجر اء المسح الميداني نم سحب عينة عثوائية من المبحوثين، و التي قوامها "Vع " طالبـاوطالبـة

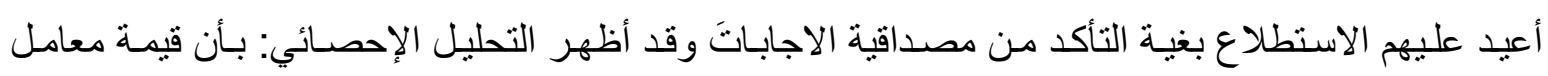

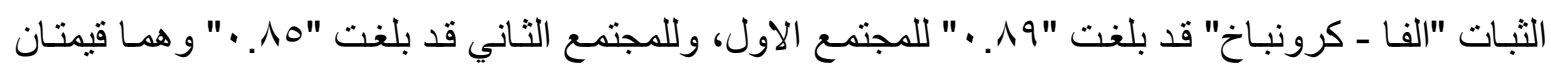
ممتازة، وتدعوان إلى قبول النتائج المترتبة على الاستطلاع، واعتمادها في البحوث و الدر اسات اللاحقة.

\section{معيار الدراسةة:}

اعتمـد مقيساس "ليكرت" الثنلاثي كمعيـار لبنـاء إستبانة الدر اسـة، وذلك مـن أجل تحديـ مدى وحدة الإدر الك، والتفاعل بين الطلبة، وكل فقرة من فقرات الدراسـة، ومن ثم كل محور بصورة عامـة من محساور

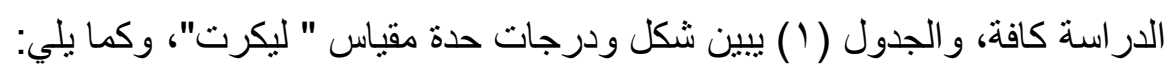

\begin{tabular}{|c|c|}
\hline التقلير النقطي & المستوى \\
\hline إدراك وتفاعل ضعيف & 1 - اقل من VI. 1 \\
\hline إدراك وتفاعل متوسط & VT. 1 - اقل من بr. \\
\hline إدراك وتفاعل قوي & $r-r . r T$ \\
\hline
\end{tabular}

جدول ( ) : يبين شكل ودرجات حدة مقياس ليكرت 


\section{التصليل الاهصائي المهور الاهصائي الديمو غرافي}

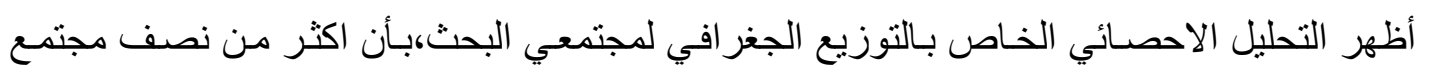

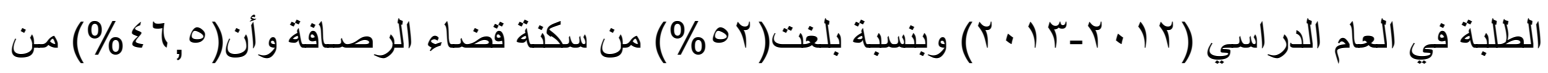
الطلبة من سكنة قضاء الكرخ، في حين مثل ماتبقى من ذلك المجتمع (0, 1\%) الطلبة القادمين من محافظـات العراق الاخرى. بينما أظهرت نتائج التحليل الاحصـائي لمجتمع المبحث الثناني و الذي يمثل الطلبـة في العـام

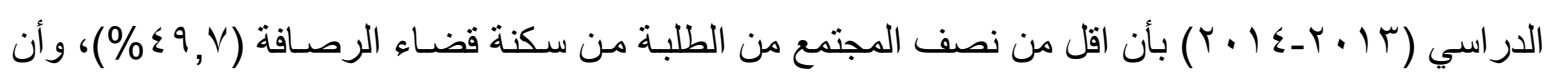
(\%乞^, l ) من محافظات العر اق الاخرى، و الجدول (r) يوضح النتائج:

\begin{tabular}{|c|c|c|}
\hline با العام الدر اسي & 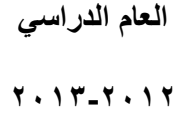 & \\
\hline \multicolumn{2}{|c|}{ النسبة المئوية } & \\
\hline$\varepsilon 9.7$ & Or & الرصافة \\
\hline$\leqslant \wedge .1$ & $\leqslant 7.0$ & الكرخ \\
\hline Y.Y & 1.0 & المحافظات \\
\hline $1 \cdots$ & $1 \cdots$ & المجموع \\
\hline
\end{tabular}

جدول (r)

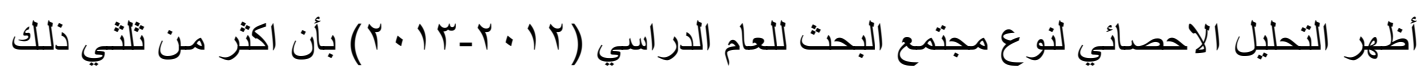

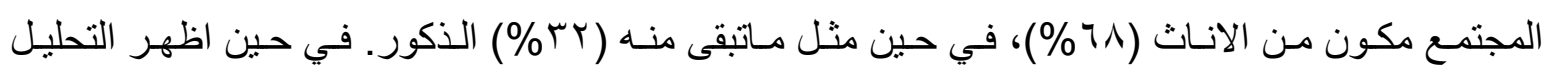

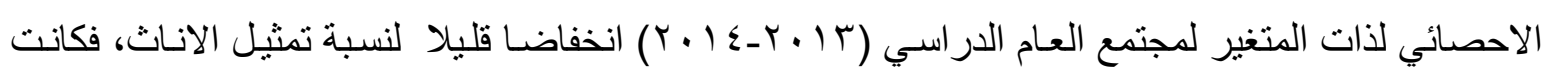

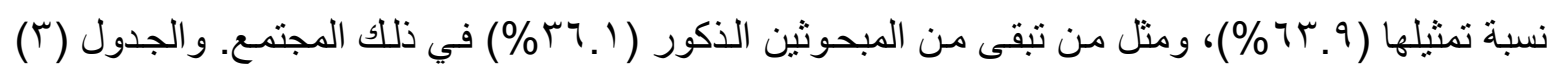
:

\begin{tabular}{|c|c|c|}
\hline العام الدراسي & العام الدر اسي & \\
\hline \multicolumn{2}{|c|}{ النسبة المئوية } & \\
\hline 74.9 & 71 & انثى \\
\hline r..1 & rr & ذكر \\
\hline $1 \ldots$ & $1 \ldots$ & المجموع \\
\hline
\end{tabular}

جدول (r)

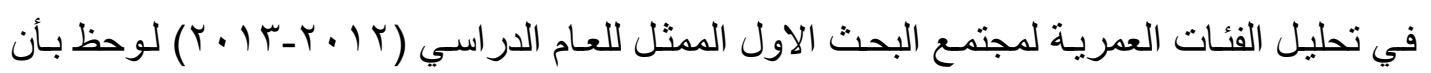

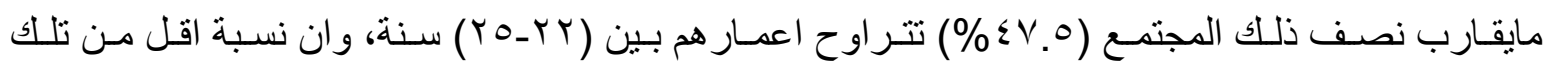




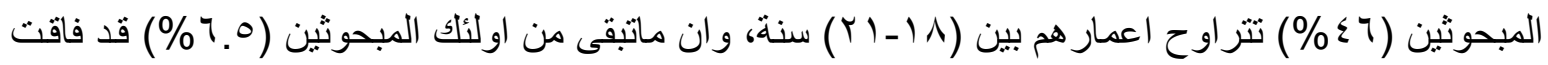
اعمار هم (Y0) سنة. بينما اظهر التحليل الاحصائي لفئات أعمار الطلبة ضمن مجتمع البحث المتعلق بالعام

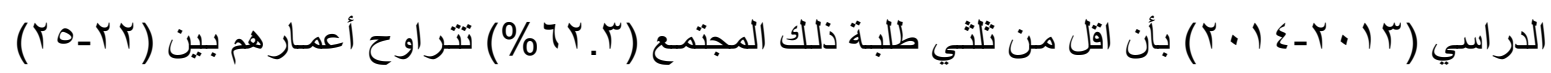

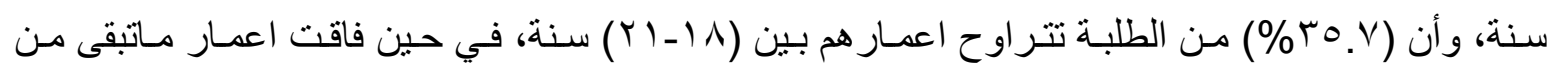

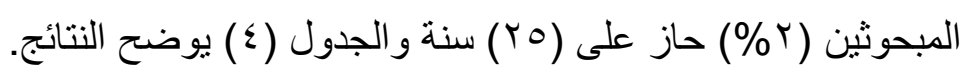

\begin{tabular}{|c|c|c|}
\hline 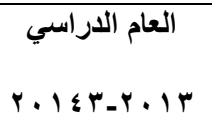 & العام الدراسي & \\
\hline \multicolumn{2}{|c|}{ النسبة المئوية } & \\
\hline ro.v & $\leqslant 7$ & $\uparrow 1-1 \wedge$ \\
\hline r.r & $\varepsilon V_{.0}$ & YO-YY \\
\hline r & 8.0 & كثر من هY \\
\hline $1 \ldots$ & $1 \cdots$ & المجموع \\
\hline
\end{tabular}

جدول (๕)

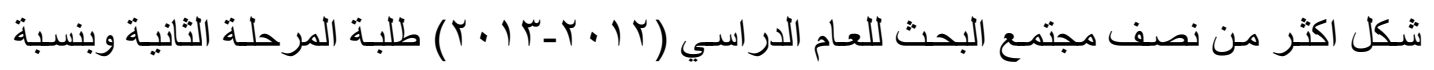
تمثيل ( (\%))، في حين شكل ماتبقى من اولئك الطلبة (9 ٪\%) للارسين في المرحلة الثالثة. في حين شكل

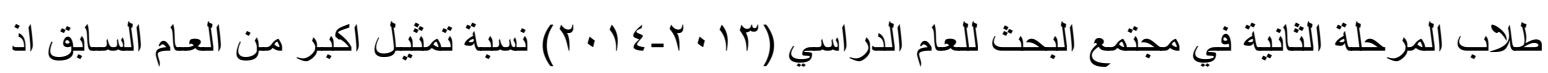
بلغت ( . ـ4\%)، وكذلك شكل ماتبقى من اولئك المبحوثين (9. س؟\%) الطلبة الدارسين في المرحلة الثالثة.

\begin{tabular}{|c|c|c|}
\hline سا العام الدراسي & العام الدراسي & \\
\hline \multicolumn{2}{|c|}{ النسبة المئويةً } & \\
\hline 04.1 & 01 & الثاثية \\
\hline$\varepsilon \% .9$ & $\varepsilon 9$ & الثالثة: \\
\hline $1 \ldots$ & $1 \ldots$ & المجموع \\
\hline
\end{tabular}

جدول (0)

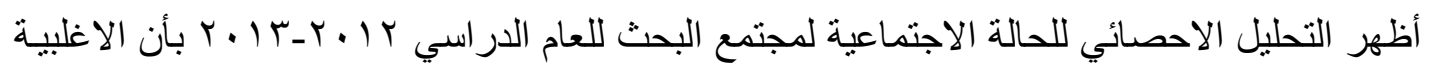

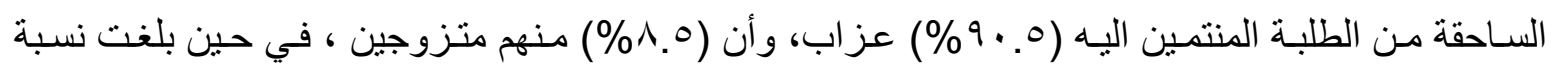
الطلبة الار امل ( (\%) من اجمالي ذلك المجتمع. اما المجتمع الثاني والممثل للطلبـة ضمن العـام الدراسي

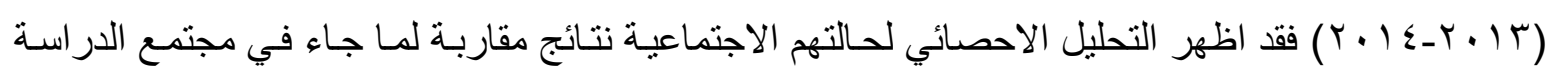

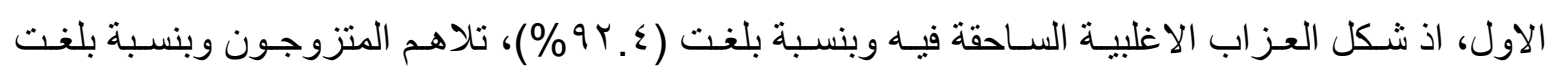

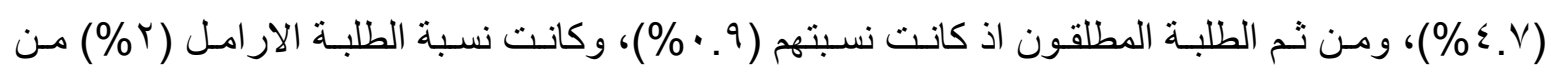

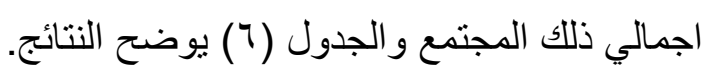




\begin{tabular}{|c|c|c|}
\hline العام الدراسي & العام الدراسي & \\
\hline \multicolumn{2}{|c|}{ النسبة المئوية } & \\
\hline $94 . \varepsilon$ & $9 \cdot .0$ & اعزب \\
\hline \&.V & 1.0 & متزوج \\
\hline 99 & صفر & مطلق \\
\hline r & 1 & ارمل \\
\hline $1 \ldots$ & $1 \ldots$ & لمجموع \\
\hline
\end{tabular}

جدول (『)

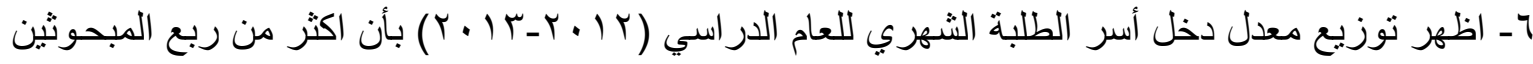

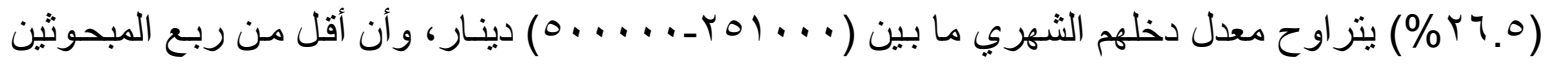

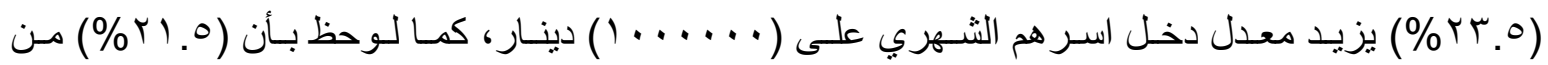

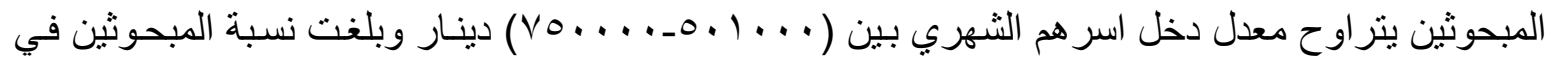

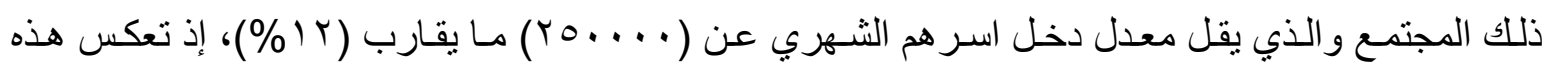
النتائج تقارباً نوعاً ما بين معدلات الدخل الثهري لأسر الطلبة قبد البحث. في حين اظهر توزيع معدل دخل

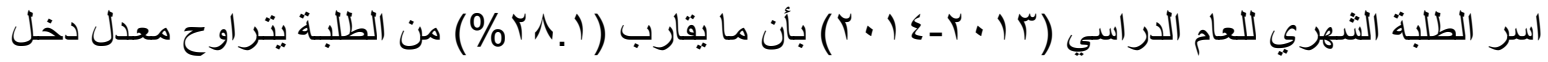

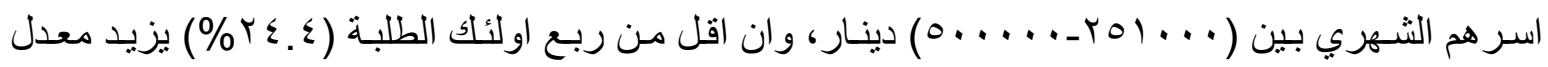

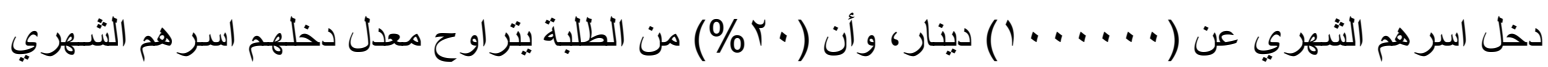

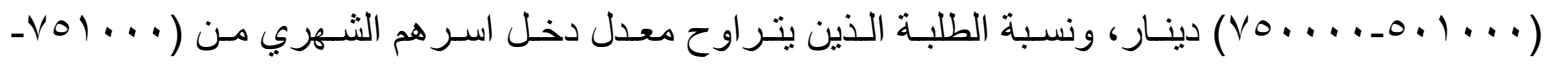

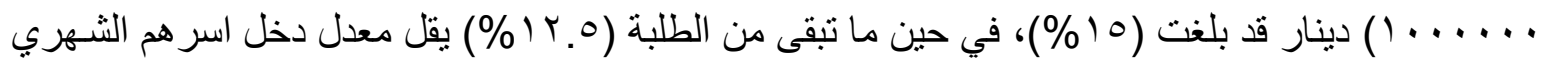

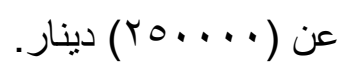

\begin{tabular}{|c|c|c|}
\hline العام الاراسي & rام العام الدراسي & \\
\hline \multicolumn{2}{|c|}{ النسبة المئوية } & \\
\hline $1 Y .0$ & Ir & اقل من ·...... \\
\hline$r \wedge .1$ & Y५.० & $0 \ldots \ldots-r 01 \ldots$ \\
\hline$r \cdot$ & 17.0 & $v 0 \ldots . ., 1 \ldots$ \\
\hline 10 & Y1.0 & $1 \ldots \ldots-v 01 \ldots$ \\
\hline$r \leqslant . \varepsilon$ & TY.O & اكثر من .... \\
\hline $1 \cdots$ & $\cdots$ & المجموع \\
\hline
\end{tabular}

جدول (V) 


\section{التهليل الاهصائي لمهور طبيعة مضموز تعليم مادة العلاقات العامة}

قـام الباحثنان بـادر اج جملـة مـن المفـاهيم و الاسـس التـي تتعلق بمفهوم بنـاء الذات وتطوير هـا لكون مبادئء العلاقات العامة تبنى على الثفافية والتنمية الذاتية في الاساس واخضعت نتائج واستجابات الطلبة الى تحليل المتوسطات. وسجل تحليل المتوسطات درجات من التفاعل عالية الثدة لجميع فقرات هذا المحور، إذ إذ الذهاء فاقت قيم الوسط الحسابي لجميع تللك الفقرات قيمة الوسط الفرضـي و البالغة (r) على مسـاحة القياس، فكان

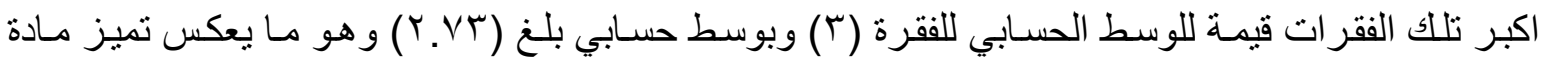

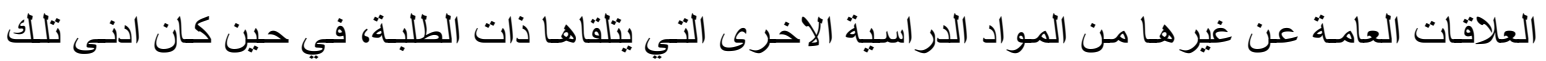

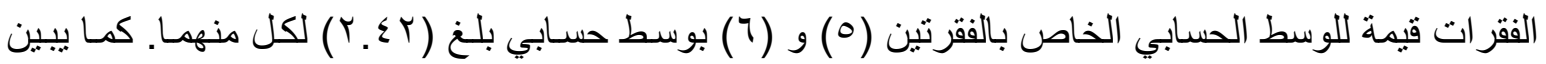
ذللك الجدول (^).

إجمالا بلغت قيمة الوسط الحسـبي العـام لكافة فقرات المحور (Y.01) وهي اكبر من قيمـة الوسط

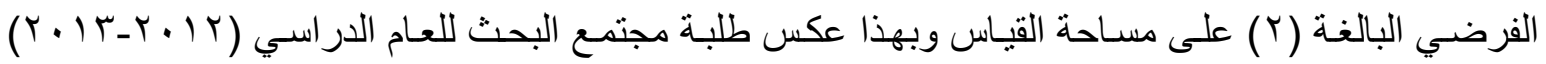
درجة استجابة وتفاعل عالية في شدتها تجاه فقرات المحور، كمـا نلاحظ بأن قيم الانحر اف المعياري لكافة

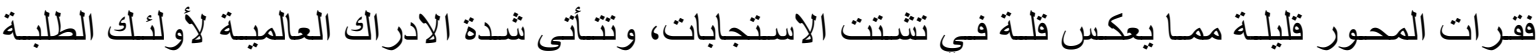
خصوصاً للدور المؤثر للنشاطات التي كانت تتخلل تعليم المـادة مما يميزهـا عن غير هـا من المواد الدراسية الاخرى ومـا لتلك النشاطات من اسـهام فعـال في حياة الطلبة أنفسهم و اقتر اب تلك النشـاطات من اخلاقيات العلاقات العامة من حيث توعيـة الطلبـة تجـاه محاربـة مفهوم الفسـاد بكافة اشكاله ، فضـلاً عن الدور المؤثر للتمارين و الالغاز و العبر المشوقة اثناء المحاضرات و التي تساعد الطلبة على فهم متغيرات حياتهم حتى بعد انتهاء مرحلة الدر اسة الجامعية والانتقال الى مرحلة حياتية جديدة، و الجدول (^) يبين النتائج.

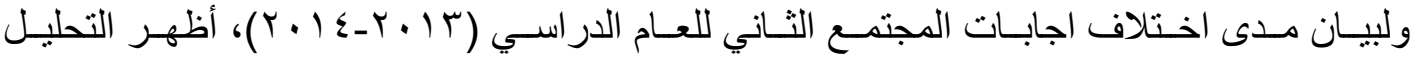
الاحصائي عبر تحليل المنوسطات لاستجابات طلبة المجتمع الثاني ذات النتائج تقريبا و التي تم الحصول عليها لمجتمع الدراسة الاول، ولكن تلك الاستجابات كانت بدرجات شدة عالية اكبر من نظير اتها الخاصـة بـالمجتمع الدر اسي الاول، إذ كانت اعلى درجات الاستجابة للفقرة (r) وبوسط حسابي قدره (Y.VY)، في حين كانت ادنى درجات استجابة للفقرة (0) وبوسط حسابي قدره (ب.or)، و الملاحظ من الجدول (^) بأن جميع الفقرات كانت بقيم اوساط أكبر من قيمة الوسط الفرضي و البالغة (r) على مساحة القياس نتيجة لتأقلم جزء من طلبـة المجتمع الاول كونهم درسوا في المرحلة الثانية ومن ثم انتقل معظمهم الى المرحلة الثالثة.

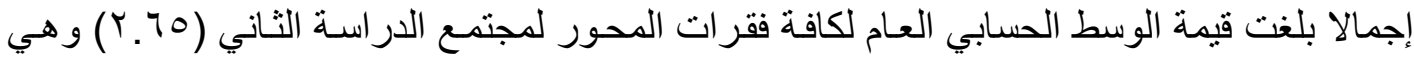
اكبر من قيمة الوسط الفرضي، وبهذا عكس طلبة مجتمع البحث الثاني درجة استجابة وتفاعل عالية الثدة تجاه محور طبيعة مضمون التعليم لمادة العلاقات العامـة وبفقرات مماتلـة لمجتمع البحث الاول و التـي شكلت اهميتها ثقل شدة الاستجابة و التفاعل العالي للطلبة، كما يلاحظ ايضاً الارتفاع النسبي في قيم الوسط الحسابي

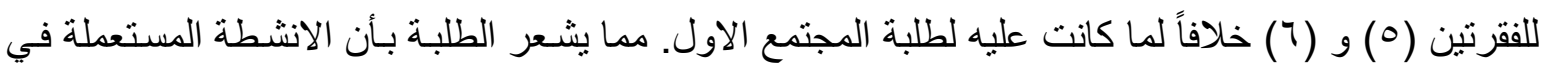
التعليم قد غيرت من تصور اتهم وسلوكياتهم كما اصبحت مرشدا لهم في حياتهم، والجدول (^) يبين النتائج. 


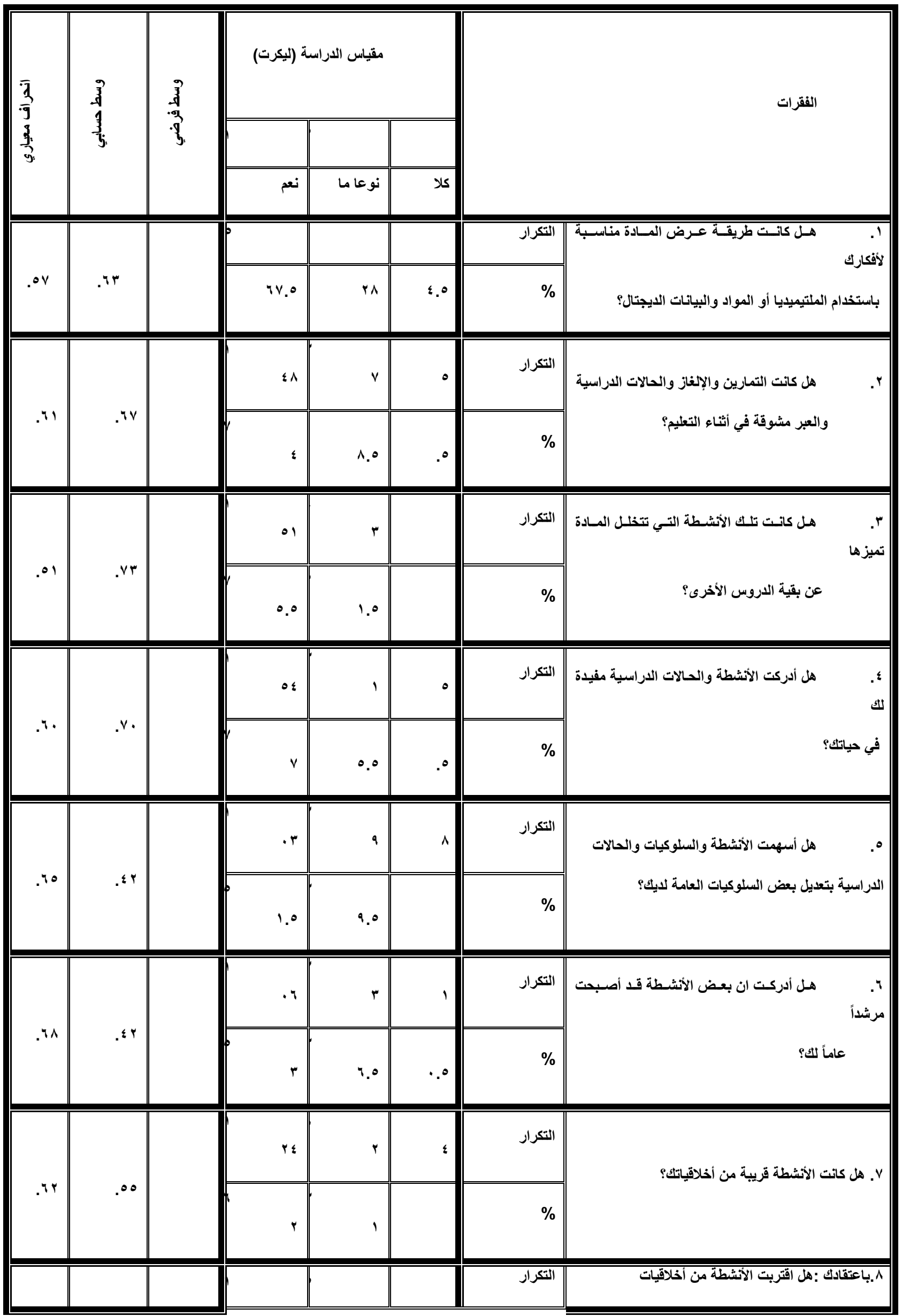




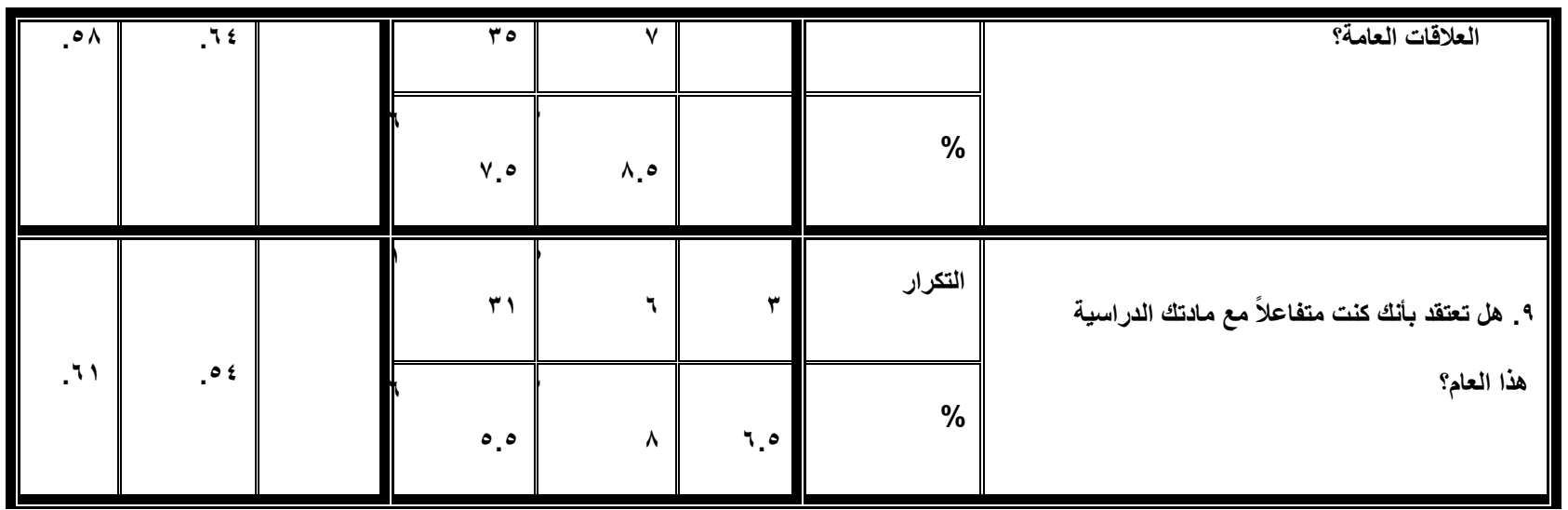

جدول (^)

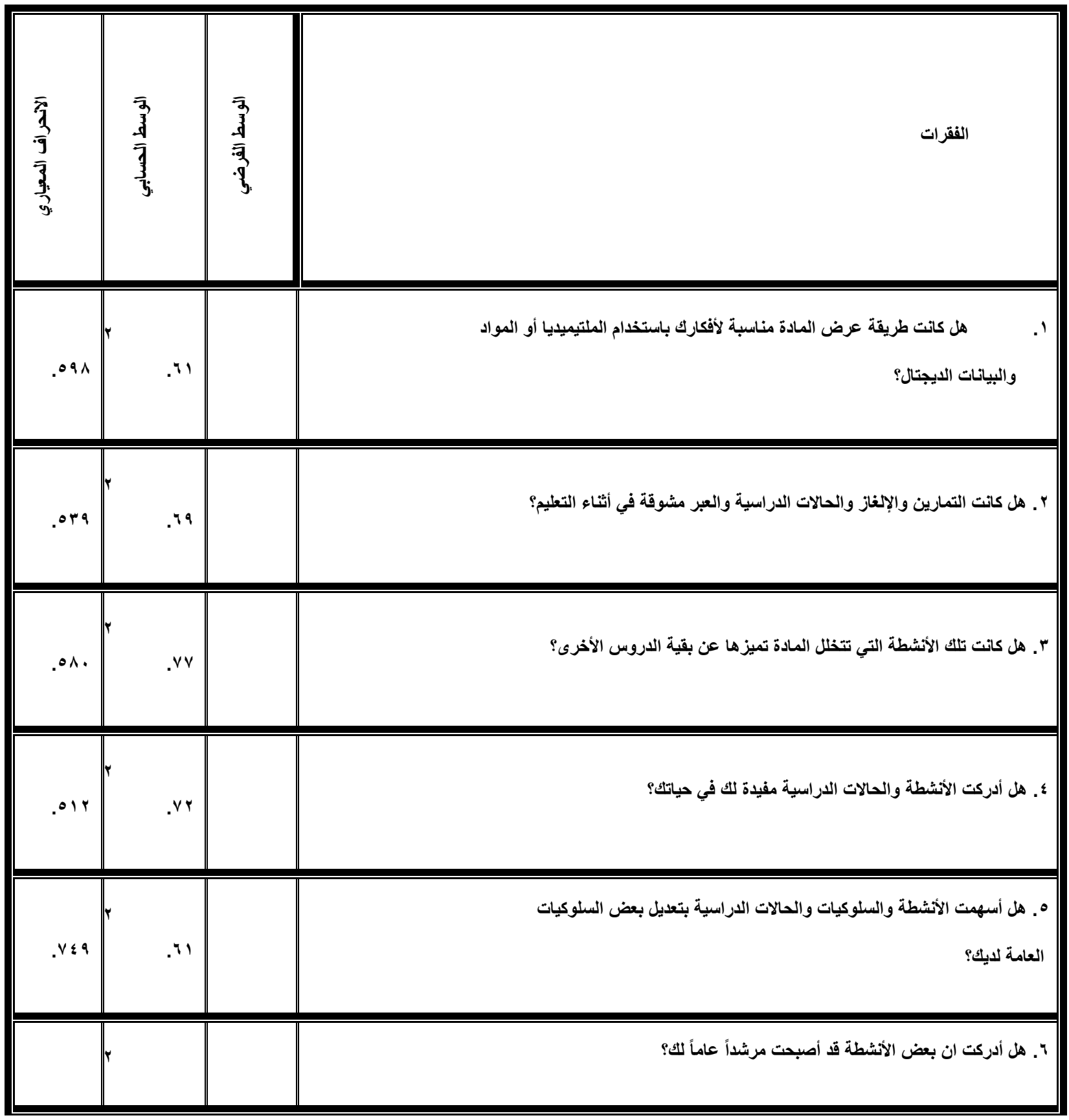




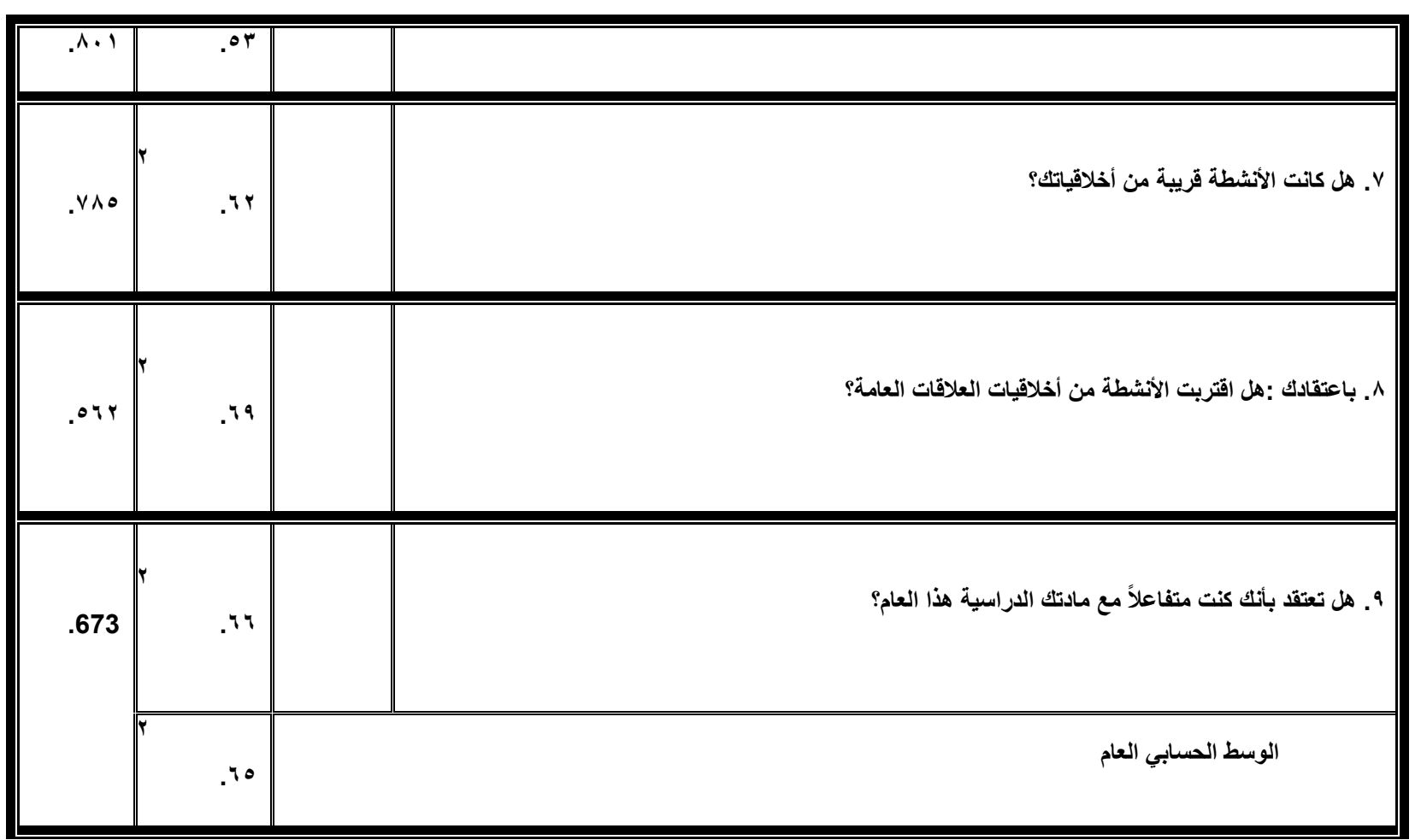

وبعد ان اظهر مجتمعـا البحث درجـة عاليـة الثدة من الاستجابة والتفاعل تجـاه مضمون ومفردات تعليم مادة العلاقات العامة نستنتج قبول الفرضية الرئيسية الاولى للبحث و التي تنص على على ((توجد درجات عالية الثدة من الاستجابة والتفاعل لطبلة كلية الاعلام حول مضمون تعليم مادة العلاقات العامة)).

\section{افتبار الفرقة بيز مدى استتجابة الطلبة هول مضمون تعليم مادة العلاقات العاهة}

بعد أن تم بيان مدى استجابة وتفاعل الطلبة في مجتمعي البحث عبر عامين در اسبين مختلفين، وبغية اختبار الفرضية الرئيسية للبحث والتي تتص على (( توجد فروقات ذات دلالة احصائية بين مدى تفاعل و واستجابة طلبـة كليـة الاعـلام حـول مضـمون تعليم مـادة العلاقـات العامـة))، تم اسـتخدام تحليل الفـرق بـين المتوسطات عبر البرنامج الاحصائي الجـاهز (SPSS) لبيان مدى معنويـة الفرق بين المتوسطات لكل من مجتمعي البحث وقد اظهرت النتائج المبينة في الجدول (9) وجود فروق ذات دلالة احصـائية بين استجابات الطلبة ضمن عامين در اسيين مختلفين وذلك لكون قيمة (P-value) اقل من (0 . • ).

\begin{tabular}{|c|c|c|c|c|c|}
\hline 2011 & مدى استج & الفارق & قيمة T المحتسبة & Sig & القرار \\
\hline عالية الثندة & عالية الثندة & $\because \cdot V$ & 4.190 & $\because .19$ & توجندية فروق \\
\hline
\end{tabular}

جذول (9)

$$
\text { وبهذا يتم قبول الفرضية الرئيسية للبحث. }
$$

إن هذه الفروقات المعنوية ذات اتجاه ايجابي نتيجـة ارتفاع قيم الوسط الحسـابي العـام لطلبـة المجتمع

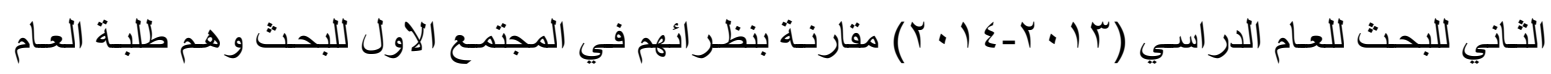




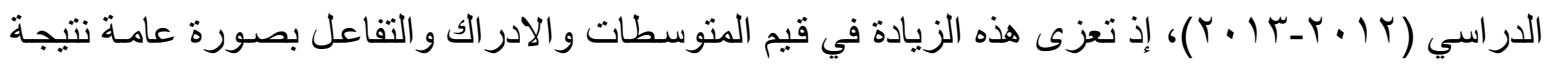

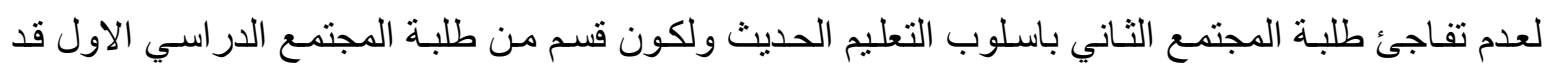
اصبحوا في مجتمع البحث الثاني (( الطلبة الناجحين من المرحلة الثانية الى المرحلة الثالثة )) و الذين قد مروا

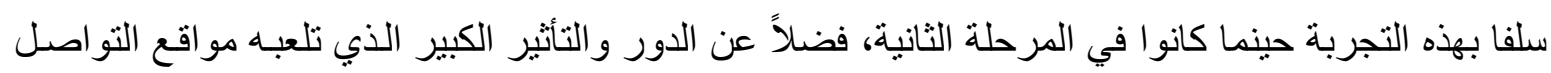
الاجتماعي و على رأسها الفيسبوك في جذب كافة شر ائح المجتمع ومنهم الطلبـة لأجل الترفيهـ و التسلية فضـلاً عن دخول موقع العلاقات العامة وتداول المادة الدراسية والاطلاع عليها.

\section{استنتاجات الجانب الاحصائي}

قبول الفرضية الرئيسية للبحث ((توجد درجات عالية الثدة من الاستجابات و التفاعل لطلبة كلية الاعلام حول مضمون تعليم مادة العلاقات العامة)).

قبول الفرضية الرئيسية الثانيـة للبحث ((توجد فروق ذات دلالة احصـائية بين استجابات وتفاعل طلبة كلية الاعلام حول مضمون تعليم مادة العلاقات العامة)).

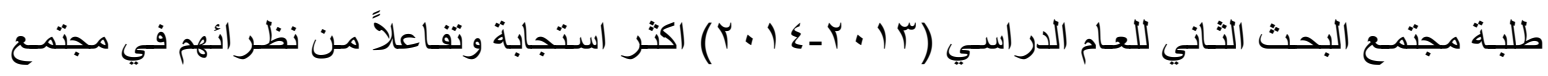

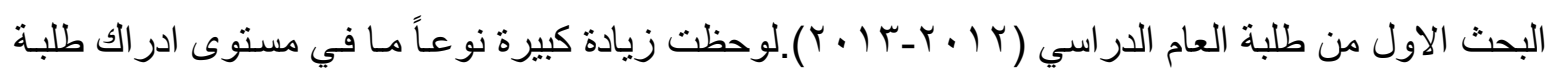
مجتمع البحث الثاني حول محور آليات التعليم الالكتروني مقارنة بنظر ائهم في مجتمع البحث الاول.

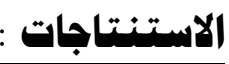

خلص البحث إلى الاستنتاجات الآتية:

1 ـ اعتمـاد الكثير مـن الدراسـات والبحـوث وطر ائق التعليم على امكانـات الملتميديا أو الوسـائل الاتصـالية الالكترونية الإعلامية وتقبل عملية التوظيف. ז- تحققت درجة من الإدراك ذات شدة متوسطة تميل إلى ان تكون عاليـة من قبَل الطلبة المبحوثين مـع

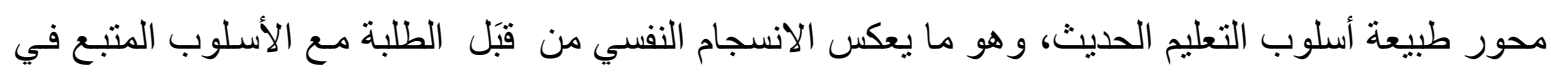
التعليم.

بـ حققت درجة من التفاعل ذات شدة عالية من قبَّل الطلبـة المبحوثين مـع محور طبيعـة مضمون التعليم

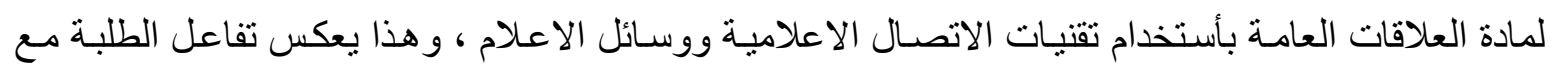
العامل الخارجي ممثلاً بأستاذ المادة، وطبيعة إيصاله للمادة الدراسية التي تركت تأثثراً كبيراً في الطلبة. عـ تحققت درجـة مـن الاستجابة إلى تقنيـات التعليم الالكتروني، وهو مـا يؤشـر استجابة الطلبـة للمتغيرات الخاصة بالتحول التكنولوجي، واستخداماته المختلفة في مواكبة الطلبة لأسلوب التعليم الحديث. هـ تضافرت عو امل ذاتية وفنية و أخرى خارجية في تنمية وتطوير إدر الك الطلبة وتفاعلهم مـع طريقة التعليم

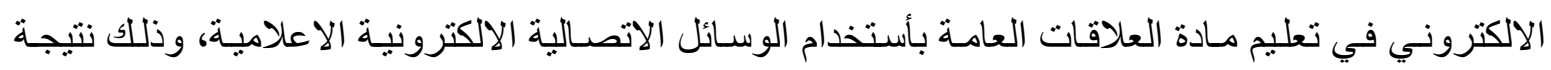

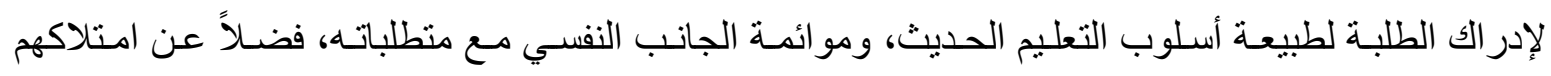


مهار ات جيدة إلى حلٍ مـا تمكنهم من استخدام الوسـائل التكنولوجيـة الحديثنة كالانترنت و الحاسـوب لمو اكبـة الأسلوب الحديث، وكذلك الدور المتميز الذي كان عاملاً خارجياً لإنجاح أسلوب التعليم الالكتروني متمثنلاً بطبيعة ومضمون مفردات المادة الدراسية، وكيفية إيصالها من قبتل أستاذ المادة إلى طلبته على وفق الحداثة و التطوير .

\section{التوصيات : بعد الاستنتاجات تم طرح التوصيات الآتية:}

ا ـ تفعيل التعليم الالكترونـي وتعميمسه على الكليات و المعاهد و المر اكز داخل الجامعـة كافة بشكل خـاص،

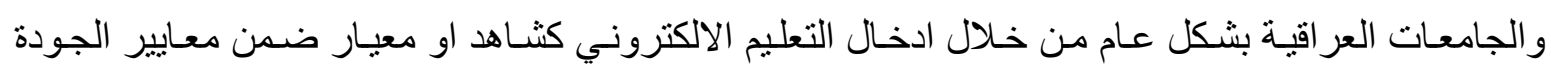

و الاعتمادية للتعليم الجامعي و الاستفادة من تقنيات وبيانات ومعلومات الوسائل الاتصالية الإعلامية. r. تطوير مناهج التعليم لتتلاءم مع آليات التقدم العلمي والتكنولوجي الحديثة، والاستفادة من تجارب الآخرين لتتو افق مع محددات المجتمع العر اقي وضـرورة سـعي الجامعات العر اقيـة وبشكل حثيث نحو الاعتماديـة من ولن الجامعات الرصينة.

r. تعزيز ثقافة التعليم الالكترونـي بين الطلبة إلى مراحل أدنى مـن التعليم الجـامعي، وتعليم المواد بشكل

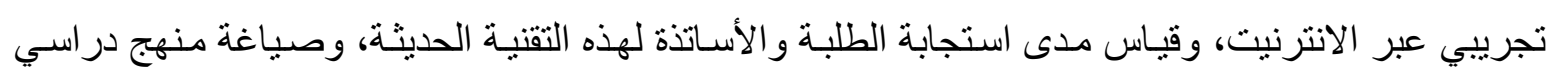

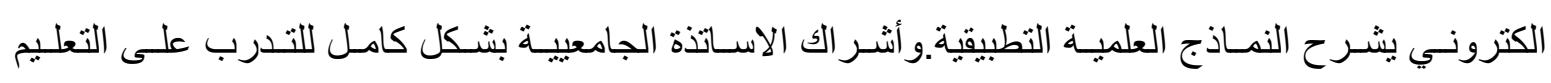
الالكتروني وتطبيقة في تعليم المواد الدراسية.

ع ـ إثـاعة و إقامة الندوات والمؤتمر ات والحلقات النقاشية و الملتقيات الالكترونيـة التي تهتم بتطوير منظومـة التعليم الكتروني تجمع الكليات العربية والأجنبية والجامعات العر اقية.

ه. استخدام نظام المحادثة كوسيلة لعقد الاجتماعات باستخدام الصوت والصورة بين أفراد المادة الواحدة مهــا

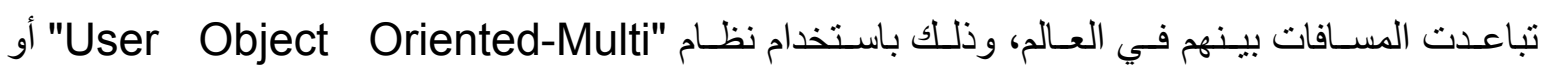
."Chat Internet Relay"

الدراسات المستقبَلية وقد تم فرض مشروع در اسات مستقبلية تضمن الآتي:

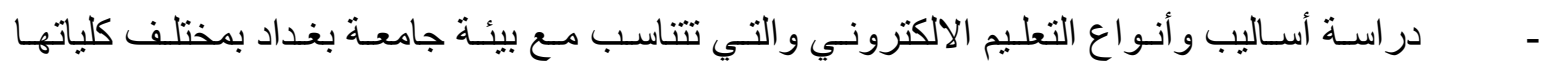
ومر اكز ها والإمكانيات الموجودة في كل مرفق فيها. كيفية استخدام الموقع التفاعلي لبث ونشر المنـاهج الدراسية لجامعة بغداد سنويا، وبشكل مباثـر من الكلية إلى المجتمع المتلقي من طلبة وأساتذة ومحترفين وهواة ومثققين و إلى غبر ذلك. - در اسـة تقوم على ربط الجامعـة بجميع مؤسسـات الدولـة العر اقيـة بـداء برئاسـة الجمهوريـة ورئاسـة مجلس الوزراء وأمانة مجلس الوزر اءو والنواب، و إمكانية اطلاع هذه المؤسسات على المحاضـر ات النموذجيـة التي تجري بالكلية من قبل أساتذة الكليات الأكفاء عبر استخدام تقنية المؤتمرات الاتصـالية المباثـرة، ونظـام 
المحادثـة كوسـيلة لعقد الاجتماعـات باسـتخدام الصـوت و الصـورة بـين أفر اد المــادة الواحدة مهمـا تباعدت المسـافات بينهم في العـالم، وذلك باستخدام نظـام "User Object Oriented-Multi" أو " Internet

.Chat Relay

\section{هوامش البحث}

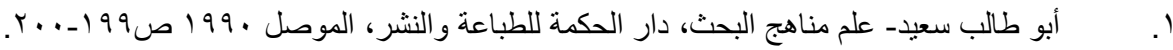

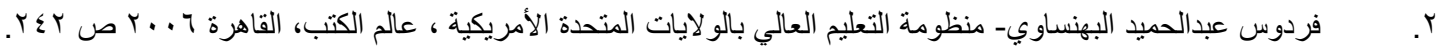
r. د. بهاء إبر اهيم كاظم، استشاري التعليم الالكتروني ومدير مركز التطوير و التعليم المستمر - جامعة بغداد.

ع. أ.م.د. شروق كاظم كلية التربية للبنات، د. بهاء إبر اهيم كاظم استشـاري التعليم الالكتروني جامعة بغداد وم.م. منتهى عبد الكريم كركز التطوير و التعليم المستمر.

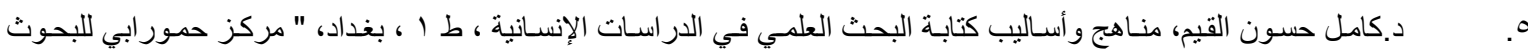

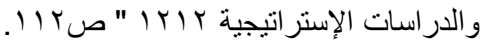

T. مجد الدين الفيروز آبادي ، القاموس المحيط ، جا ، القاهرة ، المطبعة المصرية ، سبو ا ، صه. ؟.

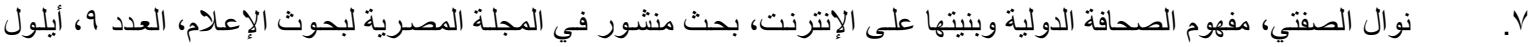
r9 ص (1991

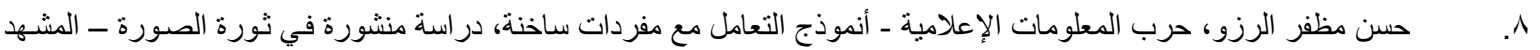

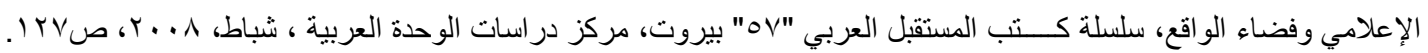

9 9. عـلاء صـالح فيـاض العبودي- توظيف الوسـائط المتعددة في المواقع الالكترونيـة الصـحفية العراقيـة رسـالة غير منشـورة، كليـة

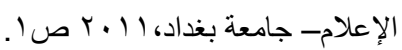

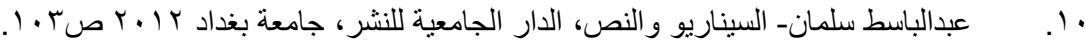

11. . علاء صالح فياض العبودي،مصدر سبق ذكره، صا.

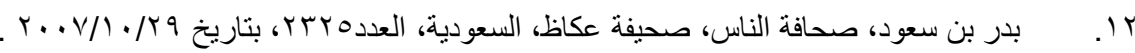

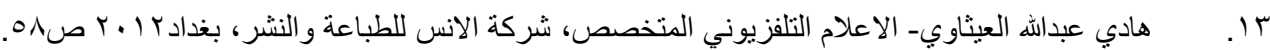

ع 1. علاء صالح فياض العبودي،مصدر سبق ذكره، صمه.

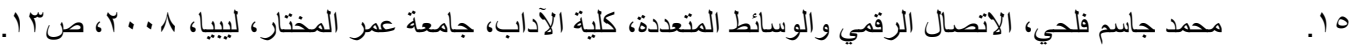

17 . . حسن صالح سليمان، تقييم وظائف اقسام العلاقات العامة في المستشفيات الخاصة الاردنية من وجهة نظر الجمهور الداخلي:دراسة

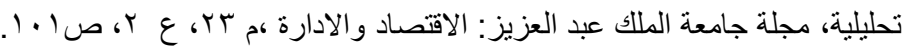

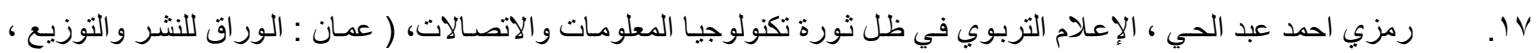

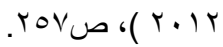

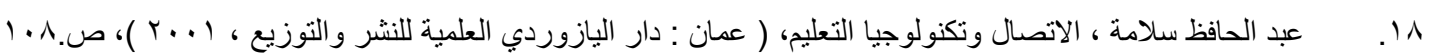

9 1. عبد الحافظ سلامة ، مصدر سبق ذكره، ص س ب ا_ـك I.

http://www.uobabylon.edu.iq، احمد محمود عبد اللطيف. التعليم الالكتروني وسيلة فاعلة لتجويد التعليم العالي. جامعة بابل.

Iร. (1) 
اب. . د. كاظم موسى عمران، التقنيات الالكترونيـة التفاعلية وتوصيف احتياجـات جامعة بغداد، ورقة عمل مقدمة إلى ملتقى جامعة بغداد للتعليم الالكتروني . r.

r . . مي حمدي حامد، التعليم الالكتروني. مادة منهجية في جامعة الزقازيق، ص.با rr. إيهاب مختار محمد، التعلم عن بعد وتحدياته للتعليم الالكتروني وأمنه، مركز التوثيق والمعلومات بوزارة الخارجية، ص.ه ع r. احمد بن عبد العزيز المبارك ، اثر التدريس باستخدام الفصول الدراسية عبر الثبكة العالمية " الانترنيت " على تحصيل طلاب كلية التربية في تقنيات التعليم والاتصال بجامعة الملك سعود ورسالة ماجستير غير منشورة. ه r. د. محمد مقداد، الدافعية إلى التعلم لدى طلبة التعليم الالكترونـي، ورقة بحث للمؤتمر الدولي الثالث حول التعليم الالكتروني، جامعة

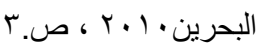
بr ـ د. عبد المجيد عثمان، التعلم الاكتروني، الوضع الراهن و آفاق المستقبل، WwW.abegs.org. V Y. فاطمة الزهر اء، محمد رشاد، المردود الايجابي للتعلم الالكتروني، مجلة التعليم الالكتروني، جامعة المنصورة، ع ه، ص ؛ .

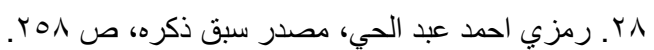
qr د.د. عبد الله بن عبد العزيز الموسى، التعليم الالكتروني مفهومه خصائصه فوائده عو ائقه، ورقة عمل مقدمة لندوة المستقبل، جامعة الملك

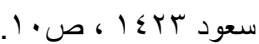
المصادر

1 أ أبو طالب سعيد- علم مناهج البحث، دار الحكمة للطباعة والنشر، الموصل . 199 r- احمد بن عبد العزيز المبارك ، اثر التدريس باستخدام الفصول الدراسية عبر الثبكة العالمية " الانترنيت " على تحصيل طلاب كلية

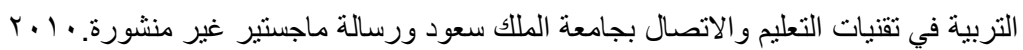
http://www.uobabylon.edu.iq، rاحمد محمود عبد اللطيف. التعليم الالكتروني وسيلة فاعلة لتجويد التعليم العالي. جامعة بابل عـ إيهاب مختار محمد، التعلم عن بعد وتحدياته للتعليم الالكتروني وأمنه، مركز التوثيق و المعلومات بوزارة الخارجية

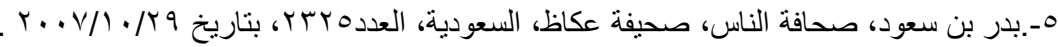
T- بهاء إبر اهيم كاظم، استشاري التعليم الالكتروني ومدير مركز التطوير و التعليم المستمر - جامعة بغداد. V- حسن صـالح سـليمان، تقيم وظـائف اقسـام العلاقـات العامـة في المستشفيات الخاصـة الاردنيـة من وجهة نظر الجمهور الداخلي:دراسـة

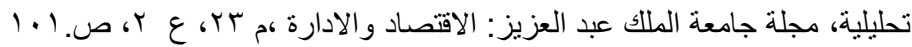
^-حسـن مظفر الرزو، حرب المعلومـات الإعلاميـة ـ أنمـوذج التعامـل مـع مفردات سـاخنة، دراسـة منشـورة في ثورة الصـورة ـ المشـهـ

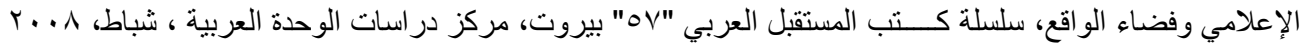
9-رمزي احمد عبد الحي ، الإعلام التربوي في ظل ثورة تكنولوجيا المعلومات والاتصالات، ( عمان : الوراق للنشر والتوزيع ، ب ا ب) . • اــ أ.م.د. شروق كاظم كلية التربية للبنات، د. بهاء إبر اهيم كاظم استشاري التعليم الالكتروني جامعة بغداد وم.م. منتهى عبد الكريم ،مركز التطوير و التعليم المستمر. الـ فاطمة الزهر اء، محمد رشاد، المردود الايجابي للتعلم الالكتروني، مجلة التعليم الالكتروني، جامعة المنصورة. r ا ـ فردوس عبدالحميد البهنساوي- منظومة التعليم العالي بالو لايات المتحدة الأمريكية ، عالم الكتب، القاهرة .7 . . ب با ا -. د. كاظم موسى عمران، التقنيات الالكترونيـة التفاعلية وتوصيف احتياجات جامعة بغداد، ورقة عمل مقدمة إلى ملتقى جامعة بغداد

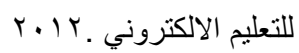
ع ا ـ د.كامل حسون القيم، مناهج وأساليب كتابة البحث العلمي في الدراسات الإنسـانية ، ط ا ، بغداد، " مركز حمور ابي للبحوث و الدراسـات

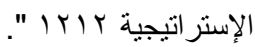


ه - عبد الحافظ سلامة ، الاتصال وتكنولوجيا التعليم، ( عمان : دار اليازوردي العلمية للنشر والتوزيع ، ( . . )؛.

ا 1 ـ د. عبد الله بن عبد العزيز الموسى، التعليم الالكتروني مفهومه خصائصه فوائده عو ائقه، ورقة عمل مقدمة لندوة المستقبل، جامعة الملك سعود r

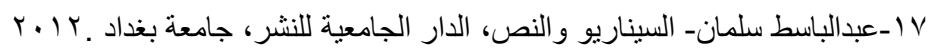
1 ا-د. عبد المجيد عثمان، التعلم الالكتروني، الوضع الراهن وآفاق المستقبل، www.abegs.org. 9 ا ـعلاء صـالح فياض العبودي- نوظيف الوسـائط المتعددة في المو اقع الالكترونيـة الصحفية العر اقيـة رسـالة غير منشورة، كلية الإعلام-

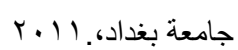
• r- مجد الدين الفيروز آبادي ، القاموس المحيط ، جا ، القاهرة ، المطبعة المصرية ، سبو19

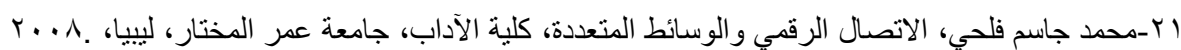
r ب - د. محمد مقداد، الدافعيـة إلى التعلم لدى طلبة التعليم الالكتروني، ورقة بحث للمؤتمر الدولي الثالث حول التعليم الالكتروني، جامعـة

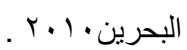
r r - مي حمدي حامد، التعليم الالكتروني. مادة منهجية في جامعة الزقازيق.

ع ب- نوال الصفتي، مفهوم الصحافة الدولية وبنيتها على الإنترنت، بحث منشور في المجلة المصرية لبحوث الإعلام، العدد 9، أيلول .1991

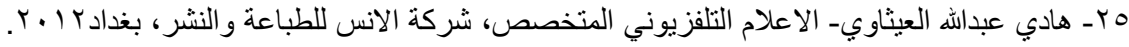

